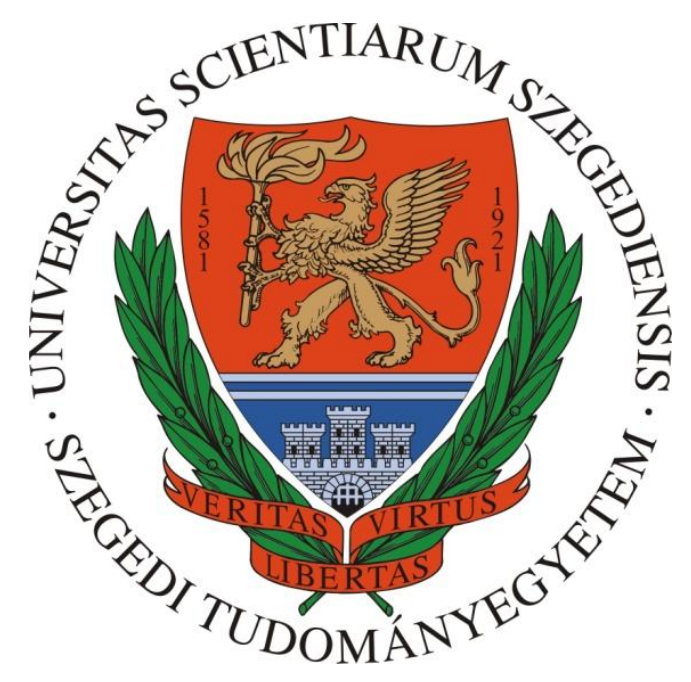

\title{
PROSPECTIVE ASPECTS IN THE ONCOLOGICAL TREATMENT OF PROSTATE CANCER
}

\section{PROSZTATA DAGANATOK KEZELÉSÉNEK ELŐREMUTATÓ ASPEKTUSAI}

Ph.D. Thesis

\section{Linda Varga, M.D.}

\author{
Supervisor: \\ Anikó Maráz, M.D., Ph.D., habil
}

Department of Oncotherapy

Faculty of Medicine, University of Szeged

Szeged, Hungary

\section{Szeged}




\section{List of full papers that served as the basis of the Ph.D. thesis}

I. Varga L, Kószó RL, Fodor E, Cserháti A, Varga Z, Darázs B, Kahán Zs, Hideghéty K, Borzási E, Szabó D, Müllner K, Maráz A. Daily Setup Accuracy, Side-effects and Quality of Life During and After Prone Positioned Prostate Radiotherapy. Anticancer Research 38:(6) pp. 3699-3705. (2018)

\section{IF: 1.935}

II. Kószó RL, Varga L, Fodor E, Kahán Zs, Cserháti A, Hideghéty K, Együd Zs, Szabó Cs, Borzási E, Szabó D, Müllner K, Varga Z, Maráz A. Prone Positioning on a Belly Board Decreases Rectal and Bowel Doses in Pelvic Intensity-Modulated Radiation Therapy (IMRT) for Prostate Cancer. Pathology and Oncology Research Pathol Oncol Res. 2019 Jul;25(3):9951002. doi: 10.1007/s12253-018-0436-2. Epub 2018 Jun 7.

\section{IF: 2.433}

III. Küronya Z, Sükösd F, Varga L, Bíró K, Gyergyay F, Géczi L, Nagyiványi K, Jorgo K, Szarvas T, Kovács Á, Laczó I, Varga Z, Pósfai B, Pepó J, Maráz A. ERG expression can predict the outcome of docetaxel combinedwith androgen deprivation therapy in metastatic hormone-sensitiveprostate cancer. Urol Oncol. 2019 Apr;37(4):289.e1-289.e9. doi: 10.1016/j.urolonc.2018.12.007. Epub 2019 Jan 21. PMID: 3067908

\section{IF: $\mathbf{2 . 8 6 3}$}




\section{Other article}

I. Varga L, Bajory Z, Pajor L, Révész J, Sükösd F, Maráz A. Edifications and modern strategies of localized prostate cancers' definitive therapy. Orv Hetil. 2018 Aug;159(32):13171325. doi: 10.1556/650.2018.31105. Hungarian.

\section{IF: 0.564}

II. Maráz A, Varga L, Küronya Z. Opportunities that improve the effectivity of immunotherapy, bringing targeted therapies into focus. Magy Onkol. 2019 Sep 18;63(3):209216. Epub 2019 Aug 13. Review. Hungarian.

III. Pósfai B, Kuthi L, Varga L, Laczó I, Révész J, Kránicz R, Maráz A. The Colorful Palette of Neuroendocrine Neoplasms in the Genitourinary Tract. Anticancer Res. 2018 Jun;38(6):3243-3254. doi: 10.21873/anticanres.12589. Review.

\section{IF: 1.935}

IV. Maráz A, Varga L. Neoadjuváns- és adjuváns kemoterápia szerepe radikális cystectomiára alkalmas urotheliális tumoros betegeknél MAGYAR UROLÓGIA 30:(1) pp. 27. (2018)

V. Maráz A, Cserháti A, Uhercsák G, Szilágyi É, Varga Z, Révész J, Kószó R, Varga L, Kahán Z. Dose escalation can maximize therapeutic potential of sunitinib in patients with metastatic renal cell carcinoma. BMC Cancer. 2018 Mar 15;18(1):296. doi: 10.1186/s12885018-4209-9.

\section{IF: $\mathbf{2 . 3 3}$}




\section{Table of contents}

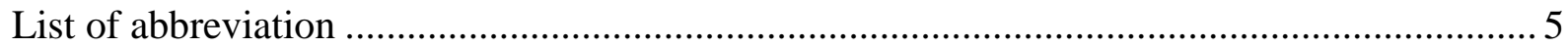

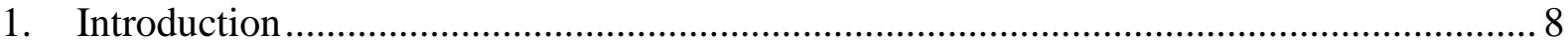

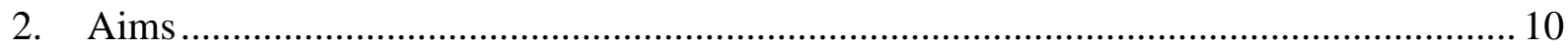

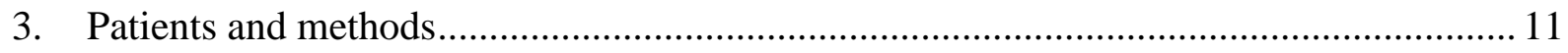

3.1. Prone positioning on a belly board decreases rectal and bowel doses in pelvic intensitymodulated radiation therapy (IMRT) for prostate cancer................................................ 11

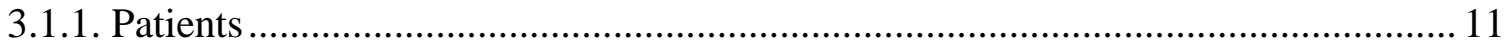

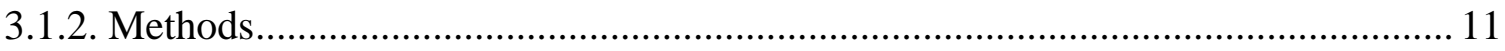

3.2. Daily setup accuracy, side-effects and quality of life during and after prone positioned

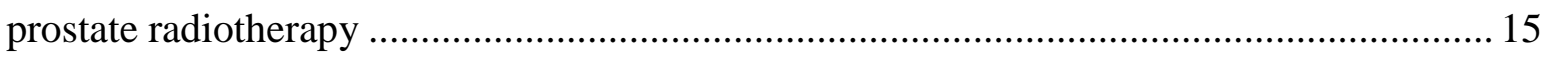

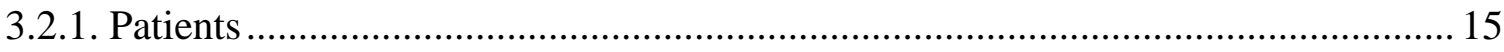

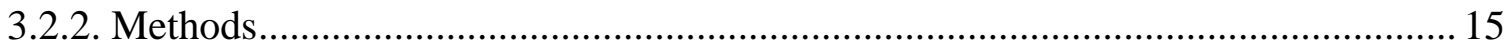

3.3. Possible predictive factors for tailored approach in metastatic hormone-sensitive

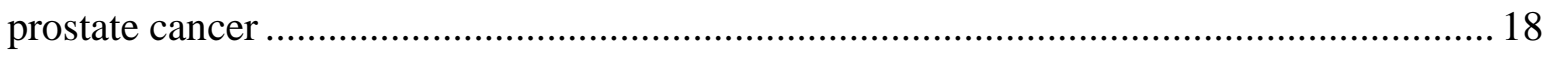

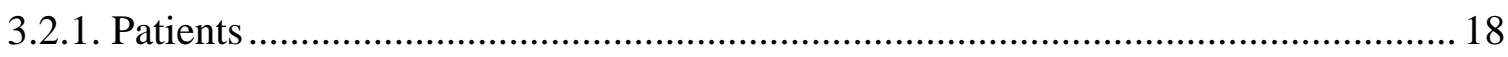

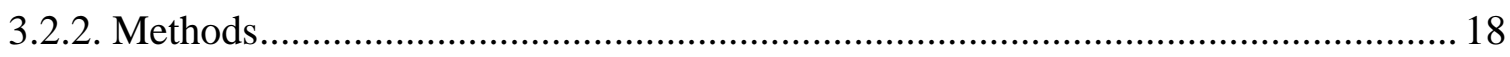

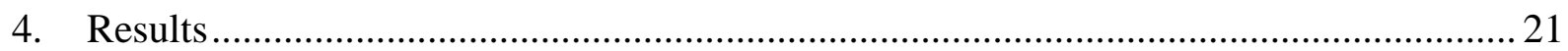

4.1. Prone positioning on a belly board decreases rectal and bowel doses in pelvic intensitymodulated radiation therapy (IMRT) for prostate cancer............................................... 21

4.2. Daily setup accuracy, side-effects and quality of life during and after prone positioned

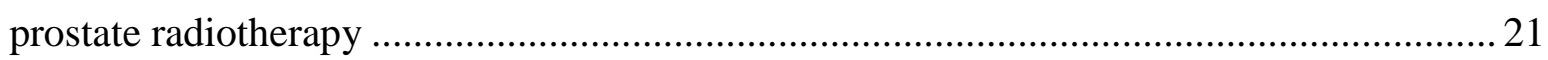

4.3. Possible predictive factors for tailored approach in metastatic hormone-sensitive prostate cancer

5. Discussion 
5.1. Prone positioning on a belly board decreases rectal and bowel doses in pelvic intensitymodulated radiation therapy (IMRT) for prostate cancer.

5.2. Daily setup accuracy, side-effects and quality of life during and after prone positioned prostate radiotherapy 32

5.3. Possible predictive factors for tailored approach in metastatic hormone-sensitive prostate cancer

6. Summary, conclusions .35

7. Acknowledgements 36

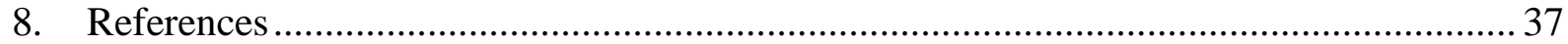

9. Appendix 


\section{List of abbreviation}

3DCRT three-dimensional conformal radiotherapy

ADT androgen deprivation therapy

AE adverse event

AIO all in one

AP antero-posterior

BB belly board

BMI body mass index

CBCT cone beam CT

ChT chemotherapy

CI confidence interval

CR castration resistant

CT computed tomography

CTCAE common terminology criteria for adverse events

CTV clinical target volume

ECOG Eastern Cooperative Oncology Group

EORTC European Organization for Research and Treatment of Cancer

ERG erythroblast transformation-specific-related gene

GETUG Genitourinary Group

GI gastrointestinal

GTV gross target volume

Gy gray

HS hormone sensitive

IGRT image-guided radiotherapy 


\begin{tabular}{|c|c|}
\hline IHC & immune-histochemical \\
\hline IMRT & intensity-modulated radiotherapy \\
\hline IPSS & international prostate symptom score \\
\hline $\mathrm{kV}$ & kilovolt \\
\hline LAT & lateral \\
\hline mCRPC & metastatic castration-resistant prostate cancer \\
\hline mHSPC & hormone-sensitive prostate cancer \\
\hline MRI & magnetic resonance imaging \\
\hline $\mathrm{mV}$ & megavolt \\
\hline $\mathrm{N}$ & node \\
\hline OAR & organ at risk \\
\hline OBL & oblique \\
\hline OS & overall survival \\
\hline $\mathrm{P}$ & prostate \\
\hline $\mathrm{PC}$ & prostate cancer \\
\hline PSA & prostate specific antigen \\
\hline PTV & planning target volume \\
\hline QOL & quality of life \\
\hline $\mathrm{R}$ & whole rectum \\
\hline $\mathrm{R} 1$ & the segment at the height of the prostate \\
\hline $\mathrm{R} 2$ & $\mathrm{R} 1+10 \mathrm{~mm}$ along the supero-inferior axis \\
\hline RFS & relapse free survival \\
\hline RT & radiotherapy \\
\hline SD & standard deviation \\
\hline
\end{tabular}


standard error

SPSS statistical product and service solutions

TCT topometric computed tomography

TNM tumour, node and metastasis

UG urogenital

VMAT volumetric modulated arc therapy

VS seminal vesicle

WHO World Health Organisation 


\section{Introduction}

Prostate cancer (PC) is the second most common malignancy worldwide; the incidence is growing in every industrial country [1]. Depending on the stage, surgical therapy, radiotherapy, and hormonal therapy are the potential options in the treatment of localized PC. In case of high risk cancers, administration of androgen deprivation therapy (ADT) is recommended simultaneously with pelvic irradiation (including the prostate, seminal vesicles, and lymphatic regions) [2].

The elevation of radiation dose significantly improves biochemical control and disease-free survival independently of the type of radiotherapy (RT), i.e. three-dimensional conformal radiotherapy (3DCRT), intensity-modulated radiotherapy (IMRT) or image-guided radiotherapy (IGRT) $[3,4]$.

The short-term and long-term side-effects of therapy are very important as PC patients usually have long survival $[2,3]$. Although RT is getting more targeted, tolerance of normal tissues limits dose escalation and increases acute and chronic gastrointestinal (GI) and urogenital (UG) morbidity, exacerbating the pre-existing urological, sexual, and psychological problems $[5]$.

Acute adverse events, occurring during or shortly after RT, include in abdominal-anorectal pain, loss of appetite, nausea, vomiting, bloating, diarrhoea, and rectal bleeding. Chronic complications occurring within 1.5 and 6 years after the completion of pelvic RT may manifest as malabsorption, lactose intolerance, fistula formation, bowel obstruction, perforation, and faecal incontinence [6].

Symptoms depend on the degree and extent of the tissue damage [7] and have a significant adverse effect on the patient's quality of life (QOL) [8]. The most important factors associated with the probability of the complications are the total dose of RT delivered to the pelvic organs, the route of administration, the size of the treatment fields, the presence of radiation implants and irradiated bowel volume [7]. 
In clinical practice, toxicity can be reduced by the use of modern radiotherapy techniques by decreasing the safety margins (e.g. IMRT, IGRT), by advantageous patient positioning and with almost constant fullness of the rectum and the urinary bladder [9].

During radiotherapy the supine position is the most frequently used laying method. Patients can be treated also in a prone position (with the use of belly board - BB), and the use of BB is associated with lower dose burden of intestines in several clinical trials of pelvic cancers formerly in the 3DCRT and nowadays in the IMRT-IGRT era [10, 11]. Rectal- and urinary bladder walls next to the prostate receive the highest irradiation dose; therefore, providing the constant fullness of these organs is necessary by using standardized bladder preparation protocol, treating patients at a fix daily time and maintaining anti-flatulence diet $[4,9]$.

Despite advances in loco-regional medical treatment, advanced or metastatic PC is still very serious problem. Systematic treatment of metastatic prostate cancer can be divided into hormone-sensitive (HS) and castration-resistant (CR) pathophysiological phases. For metastatic hormone-sensitive prostate cancer (mHSPC) until recently, androgen deprivation therapy (ADT) alone by surgical or medical castration was the standard-of-care [12]. As the disease progresses to metastatic castration-resistant prostate cancer (mCRPC), currently approved therapeutic options in Hungary are docetaxel, abiraterone acetate, enzalutamide, cabazitaxel and radium-223 [13].

Although the histological classification of prostate cancer is well-known [14], the different molecular subtypes and molecular variants may respond differently to certain therapies. In recent years, many retrospective studies have focused on identifying potential predictive factors for optimizing treatment decisions $[15,16,17]$. 


\section{Aims}

The primary aim of the dissertation is to investigate the potentially prospective aspects in the oncological treatment of PC, which provide better survival opportunities and to improve the quality of life of patients.

2.1. Determine during pelvic RT of PC patients whether a supine or prone position (on a BB) results in the reduction of the radiation dose to organs at risk (OARs), particularly the rectum, colon, and small intestines.

2.2. Evaluate the daily setup accuracy, define the necessary safety margins.

2.3. Analyse the patients' quality of life and side-effects of the therapy in case of PC patients treated with extended (with therapy of regional lymph nodes) radiotherapy in a prone position by IMRT-IGRT technique.

2.4. Investigate the possible predictive factors for tailored approach in mHSPC, that may help predict the response to docetaxel chemotherapy (ChT) as well as clinical outcomes. 


\section{Patients and methods}

All the clinical studies had been approved by the Research Ethics Committee (number of ethical approval: WHO3856/2016 and 21679-2/2016). In the two prospective analyses all the enrolled patients gave their written informed consent before being registered as participating in the study.

\subsection{Prone positioning on a belly board decreases rectal and bowel doses in pelvic intensity-modulated radiation therapy (IMRT) for prostate cancer}

\subsubsection{Patients}

Patients with histologically confirmed prostate cancer graded according to the Gleason score system [18], who have high risk [4], localized or locally advanced (2009 TNM classification [19]), stage T2-4 N0-1 M0 tumour, and receiving a definitive pelvic RT at the Department of Oncotherapy, University of Szeged, Hungary. The tumour stage assessment was based on thoracic, abdominal and pelvic computed tomography (CT), prostate magnetic resonance imaging (MRI), and whole-body bone scintigraphy. Clinical and pathological data were collected from the patient records.

\subsubsection{Methods}

\section{Patient positioning and scanning}

CT scanning was prepared with full bladder according to our internal protocol. Patients were positioned on the supine (with bent knees), and prone pelvis (with BB and a polystyrene wedge between the buttocks) modules of the All in One (AIO) Solution (ORFIT, Wijnegem, Belgium) system. For immobilization a six-point thermoplastic mask fixation (Pelvicast system, ORFIT, Wijnegem, Belgium) was used (Fig. 1). All patients underwent fivemillimeter slice-thickness topometric CT (Somatom Emotion 6 CT Simulator, Siemens, Erlangen, Germany) scanning in both positions. 

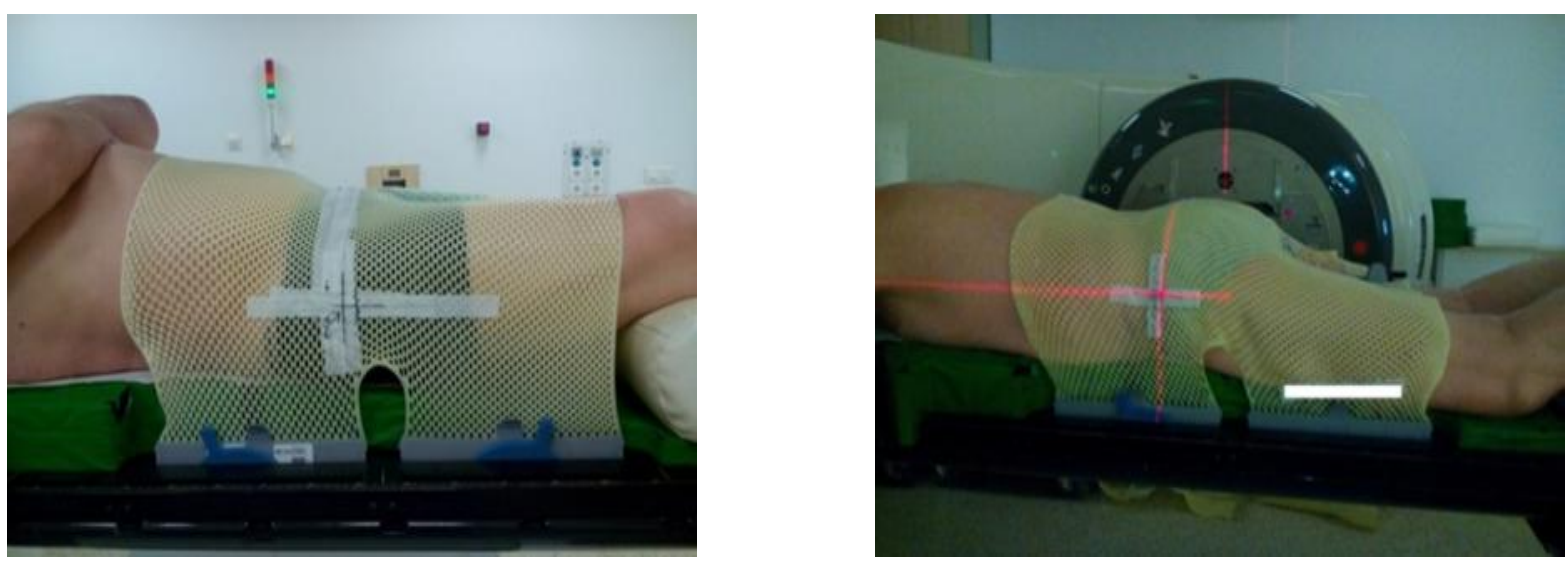

Fig.1. Topometric CT scanning in supine and prone position

\section{Target and OARs structure delineation}

In both position target volumes and OARs were delineated by radiation oncologists and reviewed by an experienced radiologist using ARIA Oncology Information System (Varian Oncology Systems, Palo Alto, CA, USA).

GTVp - prostate

GTVvs - seminal vesicle (the proximal thirds, or in case of involvement, the full extension)

GTVn - pathological lymph node, if present

CTVN - parailiac, upper subaortic presacral and obturator lymph nodes

PTVp - included GTVp with a $10 \mathrm{~mm}$ margin along the supero-inferior, left-right axis, in anterior direction and $7 \mathrm{~mm}$ in posterior direction

PTVpvs - the combination of GTVp and GTVvs with a safety margin of $10 \mathrm{~mm}$ and $15 \mathrm{~mm}$ in posterior direction and any other directions

PTV - determined as PTVpvs, a $7 \mathrm{~mm}$ margin around CTVN and $10 \mathrm{~mm}$ around GTVn, if present

The OARs were: femoral heads, and bony structures, urinary bladder (from the apex to the dome), large and small intestines (contained all identifiable segments) and rectum (from the ischial tuberosities to the sigmoid flexure) [20]. 
Each rectal section, the whole rectum $(\mathrm{R})$, the segment at the height of the prostate (R1), and $\mathrm{R} 1+10 \mathrm{~mm}$ along the supero-inferior axis (R2) were individually delineated (Fig. 2).
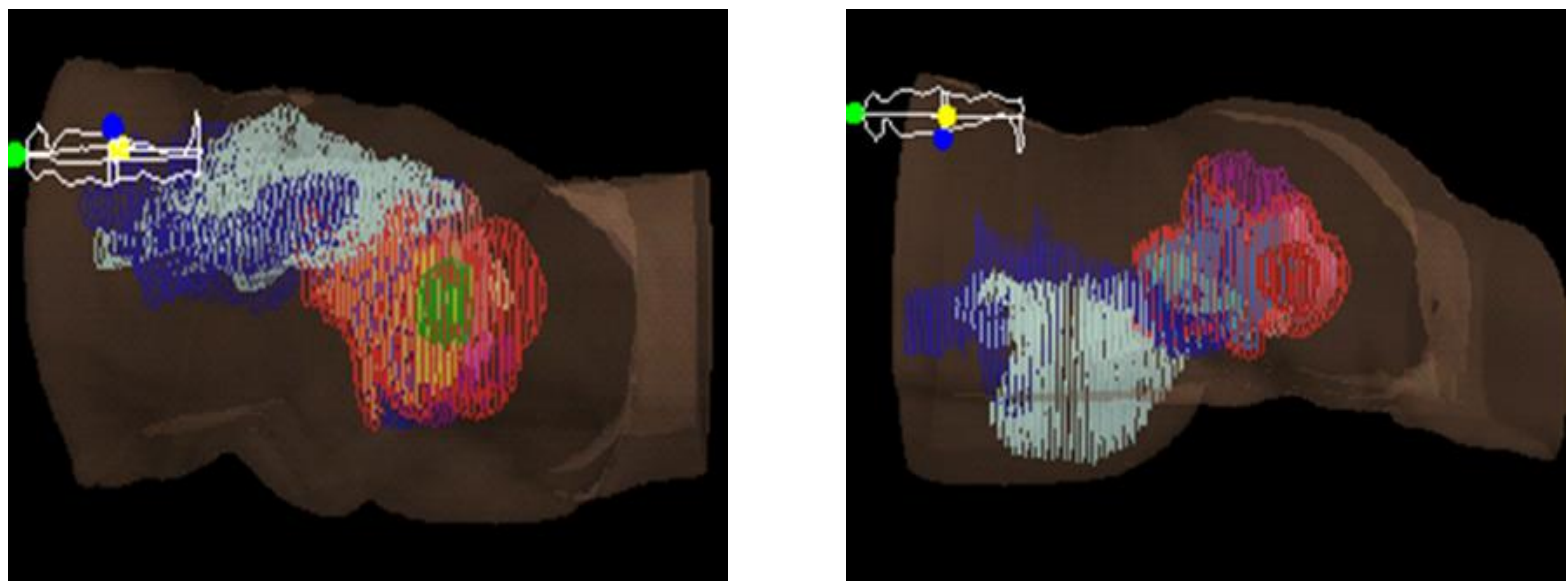

Fig.2. Target volumes and OARs delineation in supine and prone position

\section{Rectal extension and rectum-prostate distance measurement}

Two independent radiation oncologists performed rectal extension and rectum-prostate distance measurements, both of them twice. At the height of the largest antero-posterior (AP) prostate diameter, rectal diameters (AP and left-right axis) were defined, and lines were created from the center and lateral edges of the back wall of the prostate to the outer anterior rectal wall in both supine and prone positions (Fig. 3).
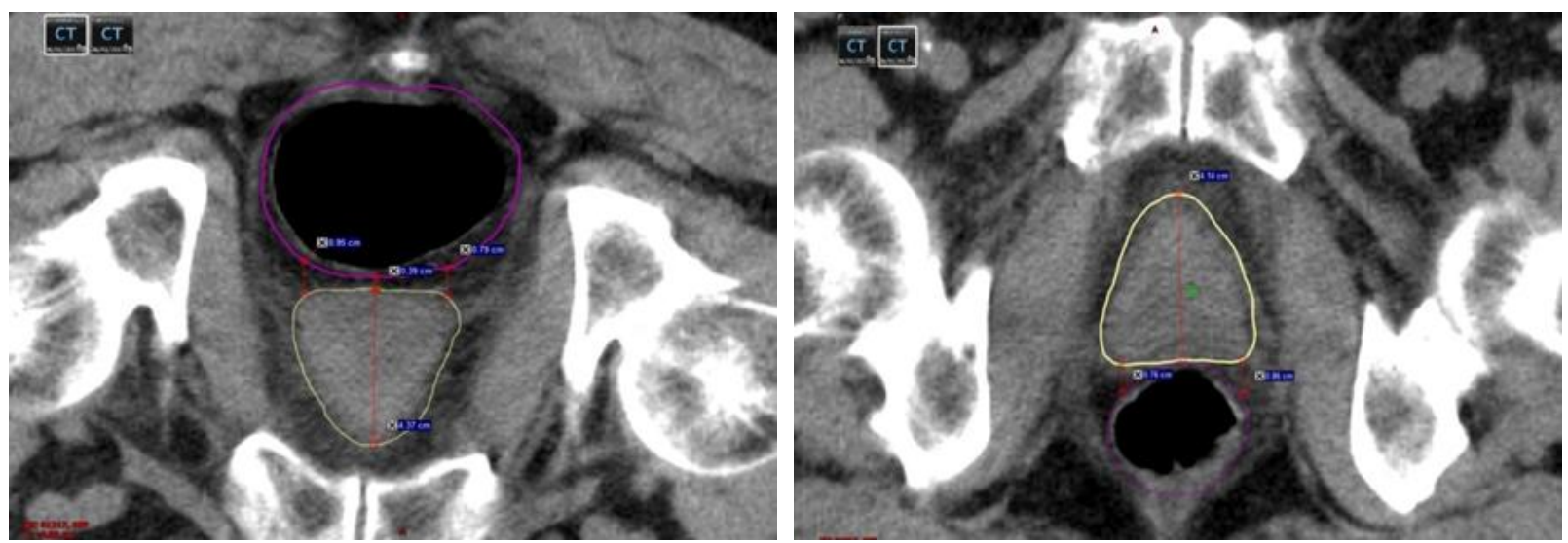

Fig.3. Rectum-prostate distance measurements in prone and supine position 
Intensity-modulated radiotherapy planning and dosimetric analysis

IMRT planning was performed using the Eclipse treatment planning system (Varian Oncology Systems, Palo Alto, CA, USA). The prescribed doses were 45 Gy to the center of the PTV (1.8 Gy/day, 5 days/week), 14 Gy of the PTVpvs and 18 Gy of PTVp, both delivered in daily 2 Gy fractions, 5 days per week. IMRT plans were created to obtain $95 \%$ coverage of the PTV with the 95\% isodose curve. For the PTV sliding window IMRT plans were designed in both positions with a seven-field beam arrangement (in prone position $0^{\circ}, 136.1^{\circ}, 208.3^{\circ}$, $258.7^{\circ}, 101.7^{\circ}, 306.1^{\circ}$ and $55.2^{\circ}$, in supine position $0^{\circ}, 38.2^{\circ}, 98^{\circ}, 142^{\circ}, 215.7^{\circ}, 269.5^{\circ}$ and $318.2^{\circ}$ ) using $6 \mathrm{MV}$ photon beam quality. For the PTVpvs and PTVp volumetric modulated arc therapy (VMAT) plans were generated in both positions $181^{\circ}-179^{\circ}$ and $179^{\circ}-181^{\circ}$ gantry angles and $30^{\circ}$ and $15^{\circ}$ collimator angles, respectively. The highest priority was PTV coverage, and the second one was the sparing of OARs.

OAR dose constraints were determined as the following:

$$
\begin{array}{ll}
\text { V55Gy }(\text { bladder }) \leq 50 \% & \text { V50Gy }(\text { colon }) \leq 50 \% \\
\text { V70Gy }(\text { bladder }) \leq 30 \% & \text { V70Gy }(\text { colon }) \leq 20 \% \\
\text { V50Gy }(\text { rectum }) \leq 50 \% & \text { V52Gy (small intestine })=0 \% \\
\text { V70Gy }(\text { rectum }) \leq 20 \% & \text { V50Gy (femoral heads })<5 \%
\end{array}
$$

\section{Radiation treatment and image-guidance}

Irradiation was carried out in prone position, by using a Varian True Beam STx (Varian Oncology Systems, Palo Alto, CA, USA). Image-guidance was based on daily kV-cone beam CT (CBCT) scanning of the pelvis prior to treatment $(125 \mathrm{kV}, 80 \mathrm{~mA}, 13 \mathrm{~ms}$, and half-fan bowtie filter), then an automatic match algorithm was used to match the bony structures displayed on the planning CT and the CBCT.

\section{Statistical analysis}

Data were reported as mean $\pm \mathrm{SD}$, mean $\pm \mathrm{SE}$ or median values. The difference between the volumes and doses in supine and prone position was analysed with the paired samples t-test. 
Intraobserver and interobserver variabilities were calculated from the mean of distances by using correlation analysis, given a correlation coefficient (r). SPSS 20.0 for Windows (SPSS Inc., Chicago, IL, USA) was used to perform the analysis. A p value $<0.05$ was considered significant.

\subsection{Daily setup accuracy, side-effects and quality of life during and after prone positioned prostate radiotherapy}

\subsubsection{Patients}

Patients with histologically-confirmed [18], localized or locally advanced (T2-4 N0-1 M0, 2009 TNM classification [19]) high risk (PSA $>20 \mathrm{ng} / \mathrm{ml}$ or Gleason score $\geq 8$ ) [4] PC was enrolled between February 2016 and June 2017. Patients with permanent urinary catheter, or who could not lie in prone position due to any co-morbidity (e.g. hip prosthesis, dyspnoea) were excluded. All patients received ADT. Stage was determined with standard methods (prostate specific antigen (PSA) level, chest X-ray or CT, abdominal and pelvic MRI, bone scintigraphy).

\subsubsection{Methods}

\section{Patient positioning, target volumes and planning}

Topometric CT was performed in prone position with BB, All in One (AIO) Solution (ORFIT, Wijnegem, Belgium), with individual immobilization system and six-point thermoplastic mask fixation (Pelvicast system, ORFIT, Wijnegem, Belgium). Polystyrene wedge was placed between the buttocks. The patient's skin was marked in accordance with the laser marks.

Standard bladder filling (drinking half litter of liquid during the 30 min before CT) and keep antiflatulence diet for 7 days before the beginning and during the therapy were recommended. Topometric CT was performed on a Somatom Emotion 6 CT simulator (Siemens, Erlangen, Germany), CT slices were acquired every $5 \mathrm{~mm}$ from the diaphragm to an imaginary line 10 $\mathrm{cm}$ below the femoral heads. Target volumes (pelvic lymph nodes, seminal vesicle and 
prostate) and organs at risk (OARs - bladder, rectum, bones, femur heads, penile bulb, small and large intestine) were delineated after MRI fusion in the ARIA Oncology Information System (Varian Oncology Systems, Palo Alto, CA, USA) with review of an experienced radiologist in all cases. For treatment planning Eclipse planning system was used (Varian Oncology Systems). Isocentric 7 fields IMRT technique was administered with inverse planning.

\section{Image-guided radiotherapy (IGRT) and determination of safety margins}

Therapy was administered five times a week with $6 \mathrm{MV}$ photon beams to 77 Gy total doses. During therapy, online and offline monitoring and data recording were performed by CBCT. After determining the systematic and random errors the CTV-PTV margin was calculated based on van Herk formula [21] $(\mathrm{A}=2.5 \cdot \Sigma$ pop $+0.7 \cdot \sigma p o p)$. In this calculated safety zone $90 \%$ of patients received $95 \%$ of prescribed dose.

\section{Daily evaluation of the rectal fullness}

The anteroposterior $\left(\mathrm{AP}, 0-180^{\circ}\right)$, the lateral (LAT, 90-270 $)$ and the oblique (OBL, 135$315^{\circ}$ ) diameters were determined in the upper and lower area of the symphysis on the topometric $\mathrm{CT}$, then during the radiotherapy on the $\mathrm{CBCT}$ in the same regions. The daily alterations of treatment time were analysed.

\section{Evaluation of side-effects and quality of life}

Side-effects were graded based on the Common Terminology Criteria for Adverse Events (CTCAE, version 4.03) [22]. Quality of life and side-effects were evaluated based on the Hungarian version of European Organization for Research and Treatment of Cancer Quality of Life (EORTC QOL - Fig. 4.) [23] and the International Prostate Symptom Score (IPSS Fig. 5.) [24] before the start of the therapy, during the 3 rd or 4 th week, after completion of therapy, and 3 and 6 months after it. 


\section{Statistical methods}

Data were reported as mean \pm SD or median values. Daily changes of rectal fullness were evaluated by the paired samples t-test. Statistical analysis (double T-test) of the questionnaires was made with IBM SPSS 20.0 (SPSS Inc., Chicago, IL, USA). A p<0.05 was considered significant.

\begin{tabular}{|c|c|c|c|c|}
\hline \multicolumn{5}{|l|}{ EORTC OLO-PR25 } \\
\hline \multicolumn{5}{|c|}{ 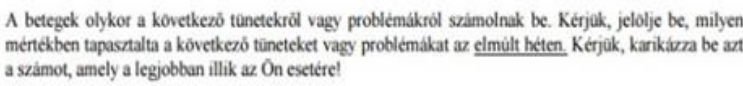 } \\
\hline Az elmúlt héten & $\begin{array}{c}\text { Egailtatin } \\
\text { neal }\end{array}$ & $\begin{array}{l}\text { Egy } \\
\text { Lisse }\end{array}$ & $\begin{array}{l}\text { Meglehe- } \\
\text { tósen }\end{array}$ & $\begin{array}{l}\text { Nagymer- } \\
\text { tekben }\end{array}$ \\
\hline 31. gakran kellett vizelnie napközbea? & 1 & 2 & 3 & 4 \\
\hline 32. gyakran kellett vizelnic tjozaka? & 1 & 2 & 3 & 4 \\
\hline $\begin{array}{l}\text { 33. amikot vizelesi ingent erzetl, sietnie kellett-e, } \\
\text { hogy elérje a vecet? }\end{array}$ & 1 & 2 & 3 & 4 \\
\hline $\begin{array}{l}\text { 34. akadalyoztae az elegendo alvashan az, hogy } \\
\text { ejsaba gyakran fel kellett kelnic vizelna? }\end{array}$ & 1 & 2 & 3 & 4 \\
\hline 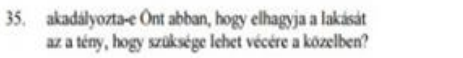 & 1 & 2 & 3 & 4 \\
\hline 36. volte onkéntelen vizelese (elseppenes)? & 1 & 2 & 3 & 4 \\
\hline 37. èzethe fajdalmat vizeléskon? & 1 & 2 & 3 & 4 \\
\hline $\begin{array}{l}\text { 38. ketjuk, erre a kérdesse cask alkor valassoljon, ha inkontinencia } \\
\text { betetet visel. Okowotr-e gondot az. inkontencia-betet viselese? }\end{array}$ & ia , & 2 & 3 & 4 \\
\hline 39. korlitonak e vixzlesi problemai mindenapi tevelenysegetben? & 1 & 2 & 3 & 4 \\
\hline 40. kortatortak-e belproblémai mindennapi tevekenysegeben? & 1 & 2 & 3 & 4 \\
\hline 41. volite onkintelen ssikletaritiese? & 1 & 2 & 3 & 4 \\
\hline 42. volt re ver a seikletichen? & 1 & 2 & 3 & 4 \\
\hline 43. etrenter uggy, mintha a has fel volna puffadva? & 1 & 2 & 3 & 4 \\
\hline 4. voltak e hOhullimai? & 1 & 2 & 3 & 4 \\
\hline $\begin{array}{l}\text { 45. tapastalta-e, hogy mellbimboja vagy melle èrzikenyebb, } \\
\text { illetve megnagyobbodort? }\end{array}$ & 1 & 2 & 3 & 4 \\
\hline 46. megdaeadt-e a latha vagy a bokaja? & 1 & 2 & 3 & 4 \\
\hline
\end{tabular}

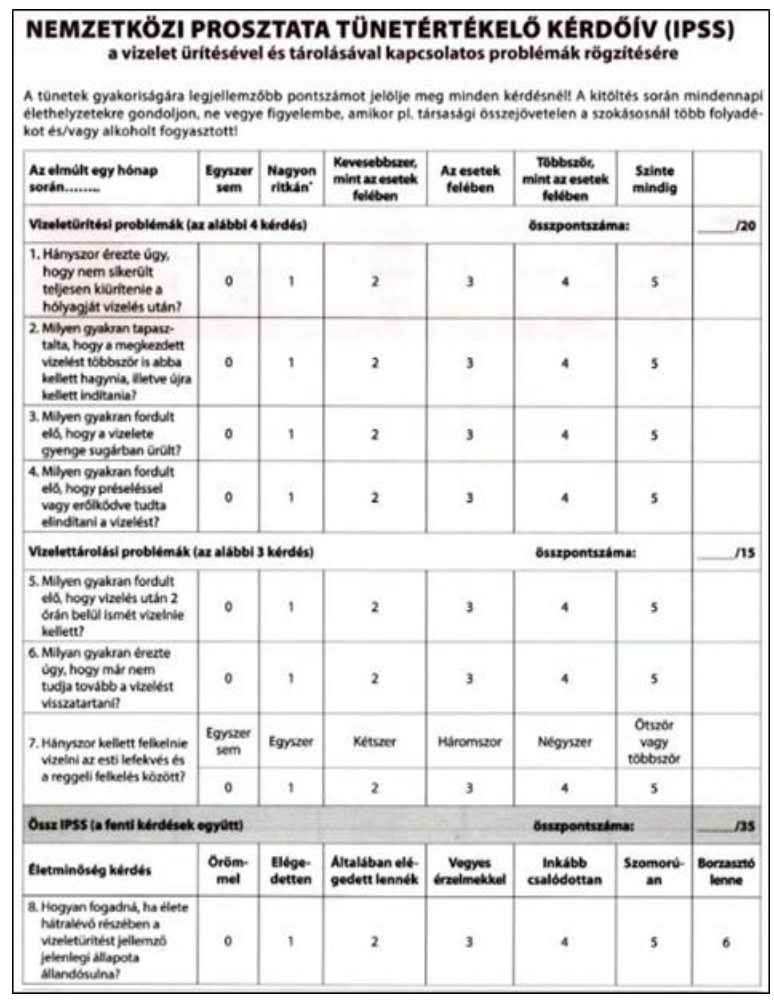

Fig.5. International Prostate Symptom Score

\begin{tabular}{|c|c|c|c|c|c|}
\hline \multicolumn{2}{|c|}{ Az elmúlt 4 héten : } & \multirow{2}{*}{$\begin{array}{c}\text { Egaltatian } \\
\text { afia } \\
1\end{array}$} & \multirow{2}{*}{$\begin{array}{c}\text { Egy } \\
\text { kise } \\
2\end{array}$} & \multirow{2}{*}{$\begin{array}{c}\text { Meglebe- } \\
\text { tósea } \\
3\end{array}$} & \multirow{2}{*}{$\begin{array}{c}\text { Nagymir- } \\
\text { telber } \\
4\end{array}$} \\
\hline 47. & okosol-e pondat Onank hogy suly a colken? & & & & \\
\hline 48. & 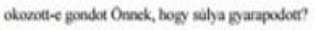 & 1 & 2 & 3 & 4 \\
\hline 49. & 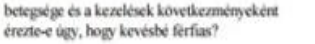 & 1 & 2 & 3 & 4 \\
\hline 50. & mennyire èdekette as szen? & 1 & 2 & 3 & 4 \\
\hline 51. & 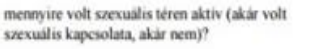 & 1 & 2 & 3 & 4 \\
\hline $\begin{array}{l}\text { kfh } \\
\text { rot }\end{array}$ & 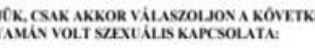 & KERDESR & I., is & & \\
\hline 52. & mennyire volt tevezetes az On szambra a sex? & 1 & 2 & 3 & 4 \\
\hline 53. & 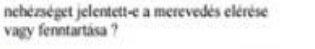 & 1 & 2 & 3 & 4 \\
\hline 54. & 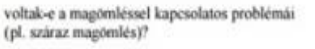 & 1 & 2 & 3 & 4 \\
\hline & $\begin{array}{l}\text { eloffordulter, hogy feszelyexve erente magit intim } \\
\text { sperulis kapcolatan? }\end{array}$ & 1 & 2 & 3 & 4 \\
\hline
\end{tabular}

Fig.4. Hungarian version of EORTC QOL 


\subsection{Possible predictive factors for tailored approach in metastatic hormone-sensitive prostate cancer}

Retrospective analysis of prospectively collected data at two Hungarian departments: the National Institute of Oncology, Budapest, and the Department of Oncotherapy, University of Szeged. All patients signed a written informed consent prior to the initiation of ChT.

\subsubsection{Patients}

Patients were eligible with mHSPC receiving docetaxel ChT between August 1, 2014 and October 31, 2017 at one of the two centers. Patients were included in the study if they had paraffin tissue blocks from diagnostic samples or metastatic sites. All tumours were objectively confirmed by histological verification, and staging procedures as well as ADT were carried out according to the conventional protocol. For each patient, treatment plan was designed by a multidisciplinary tumour board.

\subsubsection{Methods}

\section{Systemic treatment}

All patients received intravenous docetaxel ChT (every 3 weeks at a dose of $75 \mathrm{mg} / \mathrm{m} 2$ in 6 cycles depending on toxicity, without prednisone), starting within 120 days after the initiation of ADT. The use of prophylactic granulocyte colony stimulating factor was allowed. Dose reduction or delay was performed at the oncologist's decision. Physical examination and laboratory tests were carried out every 3 weeks. The severity of adverse events (AEs) was evaluated based on the National Cancer Institute Common Terminology Criteria for Adverse Events, Version 4.0 [22]. Patients' general condition was assessed using the ECOG scale [25]. Data were collected prospectively starting in August 2014.

\section{Response analysis}

The assessment of outcomes was carried out before and 8 to 12 weeks after the completion of chemotherapy and involved clinical examinations, PSA measurements, bone scan, and 
diagnostic chest-abdomino-pelvic CT examinations. Response to therapy and follow-up were assessed according to the Prostate Cancer Working Group criteria system [26]. Good response was defined as a $\geq 50 \%$ decrease in baseline PSA levels. Relapse-free survival (RFS) and overall survival (OS) were defined as the period from the initiation of ChT to the detection of castration-resistant prostate cancer or death [27]. Early progression was defined as the development of CRPC within 12 months after the initiation of ChT.

\section{ERG immune-histochemistry}

Before ChT, immune-histochemical (IHC) staining was performed to quantify ERG expression in the biopsy samples. Histological samples were obtained from different pathological departments where primary diagnoses were made. Prostate biopsy tissue samples were examined in a retrospective way with regards to ERG expression at the Department of Pathology, University of Szeged.

ERG (clone EP 111, Cell Marque \#434R-14) was diluted at 1:500, deparaffinization and rehydration at room temperature were followed by antigen retrieval with the PT Link system (10 mM sodium citrate buffer, $\mathrm{pH}$ 6.0, for 30 minutes at $94^{\circ} \mathrm{C}$; Dako, Glostrup, Denmark). After rinsing with Tris-buffered saline (EnVision FLEX Wash), the sections were placed in a Dako Autostainer Link 48 forendogenous peroxidase blockage and staining. Diaminobenzidine was used as chromogen. The sections were then counterstained with Mayer's hematoxylin, dehydrated, cleared in xylene and mounted.

Negative controls were obtained by the omission of the primary antibody. The positive controls for ERG were endothelial cells. Only subjects with nuclear ERG immunoreactivity were classified as ERG positive [28] (Fig. 6.). For the main analysis of ERG expression in relation to prostate cancer mortality, we used a dichotomous marker cut point (positive or negative for nuclear ERG immunoreactivity). 

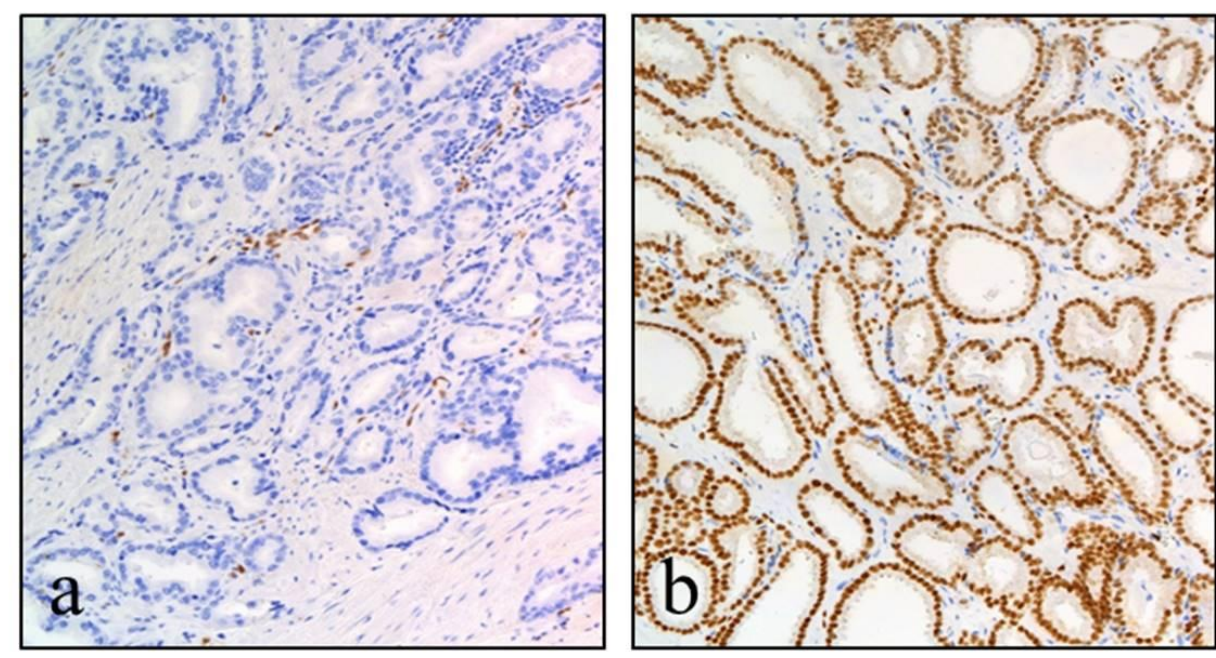

Fig.6. a) ERG negative PC (endothelial cells are the internal positive control)

b) ERG positive PC

\section{Statistical analysis}

The association between patient characteristics and RFS or OS was analysed by Kaplan-Meier analysis for categorical variables and by Cox regression for continuous variables. To detect the joint effect of the decrease in PSA level and ERG expression on RFS, multivariate Cox regression analysis (forward likelihood ratio method) was applied. All statistical analyses were performed using the IBM SPSS v22.0 software (IBM Corp. Released 2013. IBM SPSS Statistics for Windows, Version 22.0. Armonk, NY: IBM Corp). 


\section{Results}

\subsection{Prone positioning on a belly board decreases rectal and bowel doses in pelvic intensity-modulated radiation therapy (IMRT) for prostate cancer}

\subsection{Daily setup accuracy, side-effects and quality of life during and after prone positioned prostate radiotherapy}

\section{Patient characteristics}

Between 10/2016 and 10/2017 55 patients with high risk localized or locally advanced prostate cancer were administered definitive pelvic lymph node RT. Mean age of the patients was 65.60 (range $=53.33-83.49$ years) years. Most of the patients were overweight, mean BMI was 26.96 (range $=19.37-41.62 \mathrm{~kg} / \mathrm{m} 2$ ) $\mathrm{kg} / \mathrm{m} 2$. More than three-quarters of them had a cardiovascular co-morbidity, and one-third of them were smokers.

The number of patients with T2 stage was $41(74.55 \%)$, T3 stage $12(21.82 \%)$ and T4 stage 2 (3.64\%). Gleason score was 7 in 27 (48.21\%), while 8, 9 and 10 in 5 (9.09\%), 19 (33.93\%) and $4(7.14 \%)$ cases, respectively. Initial PSA level was lower than $10 \mathrm{ng} / \mathrm{ml}$ and was between 10 and $20 \mathrm{ng} / \mathrm{ml}$ in $13(23.21 \%)$ and in 9 (16.36\%) cases, respectively. In case of $33(58.93 \%)$ patients the initial PSA level was $\geq 20 \mathrm{ng} / \mathrm{ml}$.

Most of the patients received ADT therapy. A total of $52(94.55 \%)$ patients received the whole prescribed dose (77 Gy). RT had to be completed earlier in 3(5.45\%) cases (74 Gy) due to necessity of a urinary catheter during treatment.

\section{Determination of safety margins}

CTV-PTV safety margins were the following: lateral: $4.44 \mathrm{~mm}$, longitudinal: $9.69 \mathrm{~mm}$, vertical: $4.98 \mathrm{~mm}$ (Table 1).

Number of patient: 55

Number of examinations: 652 


\begin{tabular}{|l|c|c|c|c|}
\hline & Vertical (cm) & Longitudinal (cm) & Lateral (cm) & 3D vectorial (cm) \\
\hline Random error & 0.3249 & 0.6870 & 0.2862 & 0.4495 \\
\hline Systematic error & 0.1086 & 0.1955 & 0.0995 & 0.1674 \\
\hline CTV-PTV margin & 0.4987 & 0.9695 & 0.4491 & 0.7332 \\
\hline
\end{tabular}

Table 1. Determination of safety margins based on van Herk formula (CTV: clinical target volume, PTV: planning target volume)

Rectal extension, rectum-prostate distance, daily evaluation of the rectal fullness

All rectal volumes (R, R1 and R2) were significantly higher in prone position. At the height of the largest AP level of the prostate, both the AP and the lateral rectal diameters were significantly higher in prone position (Table 2).

\begin{tabular}{|c|c|c|c|c|}
\hline Structure & Position & Mean volume (cm3) & Standard deviation (SD) & $p$ value \\
\hline \multirow[t]{2}{*}{ whole rectum $(\mathrm{R})$} & prone & 155.13 & 105.26 & \multirow{2}{*}{$<0.001$} \\
\hline & supine & 95.61 & 45.89 & \\
\hline \multirow[t]{2}{*}{ rectal subsegment (R1) } & prone & 50.32 & 31.84 & \multirow{2}{*}{$<0.001$} \\
\hline & supine & 34.76 & 23.64 & \\
\hline \multirow[t]{2}{*}{ rectal subsegment (R2) } & prone & 74.37 & 41.51 & \multirow{2}{*}{$<0.001$} \\
\hline & supine & 50.78 & 27.64 & \\
\hline Rectal diameter & Position & Mean volume (cm3) & Standard error (SE) & $p$ value \\
\hline \multirow[t]{2}{*}{ AP } & prone & 50.60 & 2.20 & \multirow{2}{*}{$<0.001$} \\
\hline & supine & 36.70 & 1.50 & \\
\hline \multirow[t]{2}{*}{ lateral } & prone & 43.80 & 2.60 & \multirow{2}{*}{0.003} \\
\hline & supine & 35.90 & 1.80 & \\
\hline
\end{tabular}

Table 2. Rectal volumes and diameters 
The rectum-prostate distance measured from the center of the rear prostate wall to the outer anterior rectal wall was significantly higher in prone position. No significant differences in the distance values measured from the left and right edges of the posterior prostate wall were found. Both intraobserver and interobserver variabilities showed close correlation (Table 3).

\begin{tabular}{|c|c|c|c|c|c|c|c|}
\hline Distance & Position & Mean (mm) & $\mathbf{S E}$ & $p$ value & \multicolumn{2}{|c|}{$\begin{array}{c}\text { Intraobserver variability } \\
-\mathrm{CC}(\mathbf{r})\end{array}$} & $\begin{array}{c}\text { Interobserver } \\
\text { v. - CC (r) }\end{array}$ \\
\hline & & & & & Examiner 1 & Examiner 2 & \\
\hline \multirow{2}{*}{ Left lateral } & prone & 6.50 & 0.40 & \multirow{2}{*}{0.062} & \multirow{2}{*}{0.92} & \multirow{2}{*}{0.90} & \multirow{2}{*}{0.89} \\
\hline & supine & 5.70 & 0.40 & & & & \\
\hline \multirow{2}{*}{ Mediosagittal } & prone & 2.80 & 0.30 & \multirow{2}{*}{0.026} & \multirow{2}{*}{0.86} & \multirow{2}{*}{0.89} & \multirow{2}{*}{0.95} \\
\hline & supine & 2.20 & 0.30 & & & & \\
\hline \multirow{2}{*}{ Right lateral } & prone & 5.90 & 0.40 & \multirow{2}{*}{0.173} & \multirow{2}{*}{0.80} & \multirow{2}{*}{0.74} & \multirow{2}{*}{0.78} \\
\hline & supine & 5.40 & 0.40 & & & & \\
\hline
\end{tabular}

Table 3. Rectum-prostate distance in prone and supine position (SE: standard error, CC: correlation coefficient)

The exposure of all rectal segments was more favourable in prone position in dose ranges of 40 to 75 Gy. The relative volume receiving $30 \mathrm{~Gy}$ dose was lower in respect of R1 segment (Table 4).

\begin{tabular}{|c|c|c|c|c|c|}
\hline OAR & DVH parameter & Position & Mean relative volume (\%) & SD & p value \\
\hline \multirow{10}{*}{$\begin{array}{l}\text { whole rectum } \\
\text { (R) }\end{array}$} & \multirow{2}{*}{ V 30Gy } & prone & 106.40 & 118.98 & \multirow{2}{*}{0.296} \\
\hline & & supine & 89.60 & 7.46 & \\
\hline & \multirow{2}{*}{ V 40Gy } & prone & 65.79 & 14.96 & \multirow{2}{*}{$<0.001$} \\
\hline & & supine & 78.58 & 10.14 & \\
\hline & \multirow{2}{*}{ V 50Gy } & prone & 35.51 & 13.83 & \multirow{2}{*}{$<0.001$} \\
\hline & & supine & 48.38 & 12.29 & \\
\hline & \multirow{2}{*}{ V 60Gy } & prone & 17.45 & 8.18 & \multirow{2}{*}{$<0.001$} \\
\hline & & supine & 24.04 & 9.11 & \\
\hline & \multirow{2}{*}{ V 70Gy } & prone & 7.57 & 4.10 & \multirow{2}{*}{$<0.001$} \\
\hline & & supine & 10.43 & 4.97 & \\
\hline
\end{tabular}




\begin{tabular}{|c|c|c|c|c|c|}
\hline & \multirow{2}{*}{ V 75Gy } & prone & 3.67 & 2.61 & \multirow{2}{*}{0.021} \\
\hline & & supine & 4.58 & 3.19 & \\
\hline \multirow{8}{*}{$\begin{array}{c}\text { rectal } \\
\text { subsegment } \\
(\mathbf{R} 1)\end{array}$} & \multirow{2}{*}{ V 30Gy } & prone & 99.78 & 0.75 & \multirow{2}{*}{0.735} \\
\hline & & supine & 99.80 & 0.61 & \\
\hline & \multirow{2}{*}{ V 40Gy } & prone & 80.58 & 13.50 & \multirow{2}{*}{$<0.001$} \\
\hline & & supine & 94.95 & 5.74 & \\
\hline & \multirow{2}{*}{ V 50Gy } & prone & 52.25 & 14.18 & \multirow{2}{*}{$<0.001$} \\
\hline & & supine & 68.55 & 10.90 & \\
\hline & \multirow{2}{*}{ V 60Gy } & prone & 32.37 & 10.90 & \multirow{2}{*}{$<0.001$} \\
\hline & & supine & 40.49 & 10.13 & \\
\hline & \multirow{2}{*}{ V 70Gy } & prone & 16.51 & 5.83 & \multirow{2}{*}{$<0.001$} \\
\hline & & supine & 20.74 & 7.14 & \\
\hline & \multirow{2}{*}{ V 75Gy } & prone & 8.79 & 4.52 & \multirow{2}{*}{0.099} \\
\hline & & supine & 9.97 & 5.67 & \\
\hline \multirow{12}{*}{$\begin{array}{c}\text { rectal } \\
\text { subsegment } \\
\quad(\text { R2) }\end{array}$} & \multirow{2}{*}{ V 30Gy } & prone & 99.52 & 1.21 & \multirow{2}{*}{0.001} \\
\hline & & supine & 98.61 & 1.96 & \\
\hline & \multirow{2}{*}{ V 40Gy } & prone & 78.55 & 12.66 & \multirow{2}{*}{$<0.001$} \\
\hline & & supine & 91.45 & 6.05 & \\
\hline & \multirow{2}{*}{ V 50Gy } & prone & 49.40 & 13.14 & \multirow{2}{*}{$<0.001$} \\
\hline & & supine & 64.83 & 9.89 & \\
\hline & \multirow{2}{*}{ V 60Gy } & prone & 28.95 & 9.04 & \multirow{2}{*}{$<0.001$} \\
\hline & & supine & 37.43 & 8.76 & \\
\hline & \multirow{2}{*}{ V 70Gy } & prone & 13.52 & 4.75 & \multirow{2}{*}{$<0.001$} \\
\hline & & supine & 17.86 & 5.79 & \\
\hline & \multirow{2}{*}{ V 75Gy } & prone & 6.82 & 3.59 & \multirow{2}{*}{0.051} \\
\hline & & supine & 7.86 & 4.43 & \\
\hline
\end{tabular}

Table 4. Exposure of rectal segments in prone and supine position (SD: standard deviation)

The data of mean AP, LAT and OBL diameters in the upper and lower area of the symphysis on the topometric $\mathrm{CT}$ rather than during the therapy on the CBCT in the same region and the daily alterations of treatment time are recorded in Table 5. Mean difference was counted from the mean results on topometric CT minus the mean results of cone beam CT. In the upper area of the symphysis the diameters of the rectal wall were significantly different, but in the lower area of the symphysis -in the region of the prostate there - could not any significant difference detected. 


\begin{tabular}{|c|c|c|c|c|c|c|}
\hline $\begin{array}{c}\text { Diameters of } \\
\text { rectum }\end{array}$ & $\begin{array}{l}\text { Mean results on } \\
\text { TCT }(\mathrm{cm})\end{array}$ & $\begin{array}{l}\text { Mean diff. } \\
\quad(\mathrm{cm})\end{array}$ & SD & \multicolumn{2}{|c|}{$\begin{array}{l}\text { 95\% CI of the } \\
\text { difference }\end{array}$} & p value \\
\hline & & & & Lower & Upper & \\
\hline \multicolumn{7}{|c|}{ Upper area of the symphysis } \\
\hline $\mathrm{AP}$ & 4.36 & 0.169 & 0.407 & 0.059 & 0.279 & 0.003 \\
\hline LAT & 3.95 & 0.193 & 0.578 & 0.037 & 0.349 & 0.016 \\
\hline OBL & 4.12 & 0.107 & 0.339 & 0.016 & 0.199 & 0.023 \\
\hline \multicolumn{7}{|c|}{ Lower area of the symphysis } \\
\hline AP & 2.80 & 0.018 & 0.112 & -0.012 & 0.048 & 0.239 \\
\hline LAT & 2.58 & -0.007 & 0.106 & -0.036 & 0.021 & 0.621 \\
\hline OBL & 2.67 & 0.029 & 0.227 & -0.032 & 0.090 & 0.347 \\
\hline
\end{tabular}

Table 5. Analysis of rectal diameters daily alteration during treatment. (AP: antero-posterior, LAT: lateral, OBL: oblique, TCT: topometric computer tomography, diff.: difference, SD: standard deviation, CI: confidence interval)

In the upper area of the symphysis the diameters of the rectal wall were significantly different, but in the lower area of the symphysis - in the region of the prostate - no significant differences were detected (Figure 7).

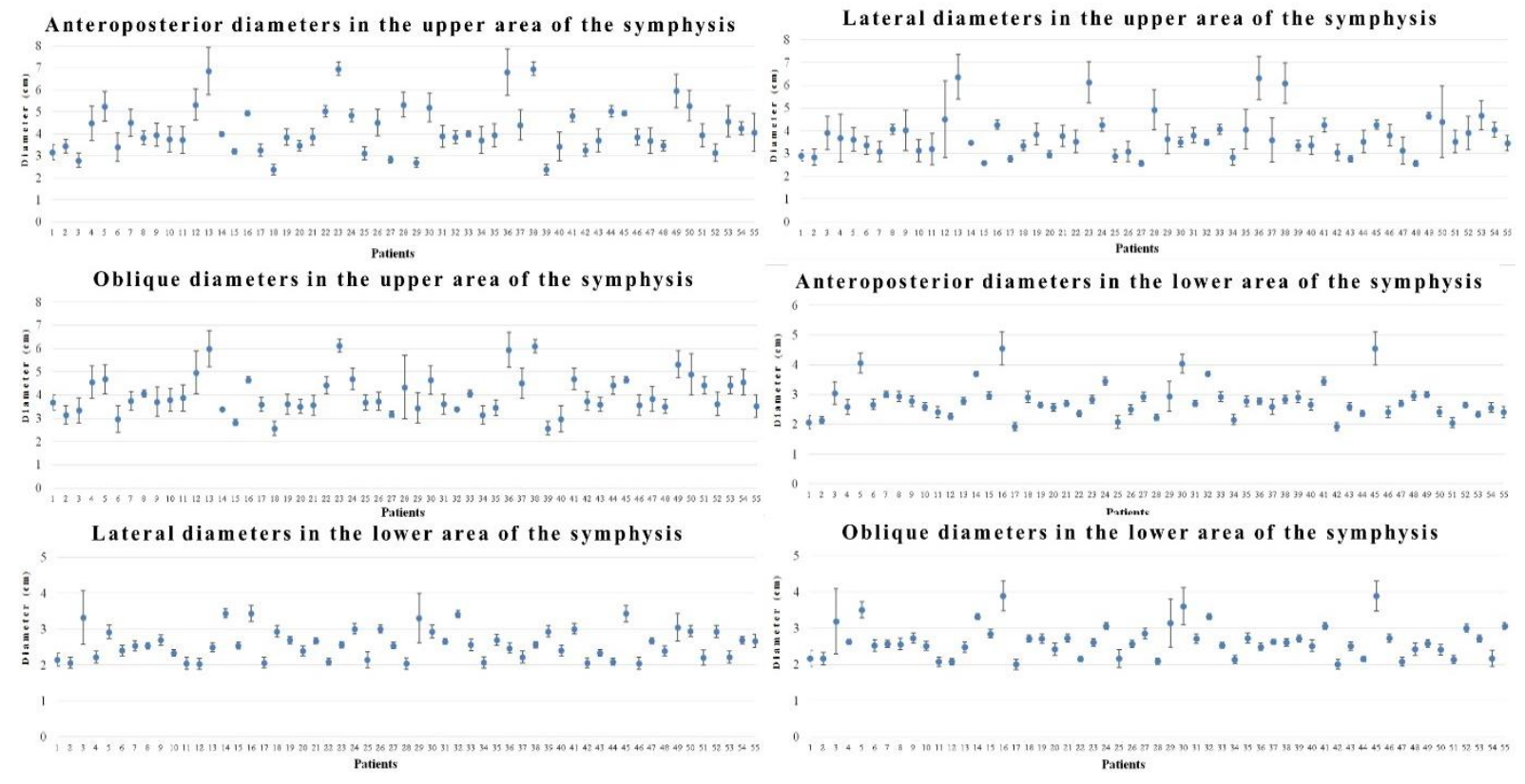

Fig.7. Rectal diameter alteration in the upper and lower area of the symphysis 


\section{Side-effects and quality of life}

The most common acute side-effects were cysto-urethritis and radiation induced enteroproctitis. Almost half and a quarter of the patients complained of GU and GI side-effects, respectively. Temporary urinary catheter was needed in 3 patients. Almost all patients had hot flashes and erectile dysfunction of different grade, but only $40 \%$ of them experienced significant complaints. Median period of follow-up was 6 months (range=3-12 months). The most important acute and late (3 and 6 months) side-effects are shown in Figure 8.

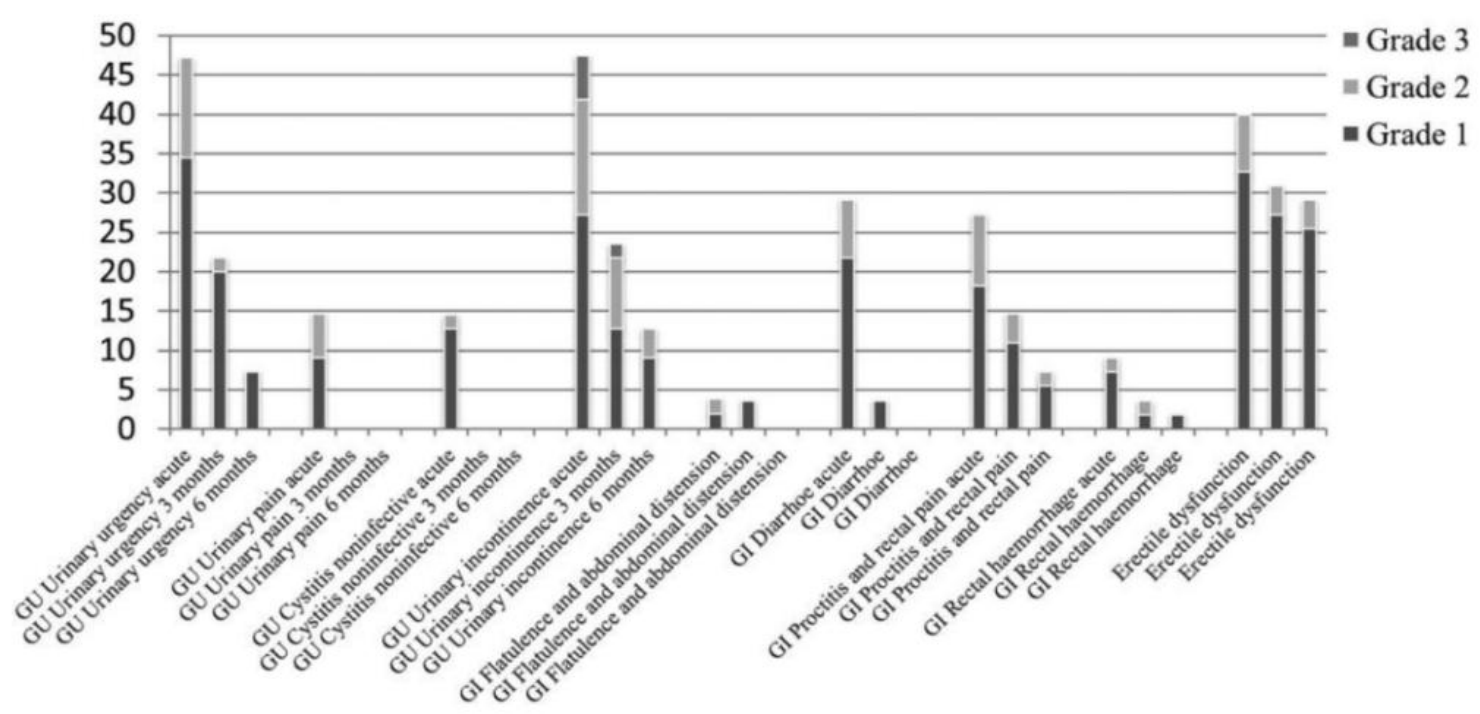

Fig.8. The most important acute and late (3 and 6 months) genitourinary (GU) and gastrointestinal (GI) side-effects

Based on the EORTC QOL, urination and defecation were significantly worse during the therapy than before. These complaints improved significantly after 3 and 6 months. Erectile dysfunction was detected in more than one third of patients initially and this rate decreased during the radiotherapy. Evaluation of the patients' sexual life was quite difficult because psychological factors may influence the patients' answers and erectile function can be also worsened by ADT. Based on total evaluation of the EORTC QOL, the patients' quality of life did not change significantly during therapy, although significant improvements could be detected in 3 and 6 months after therapy (Figure 9). 

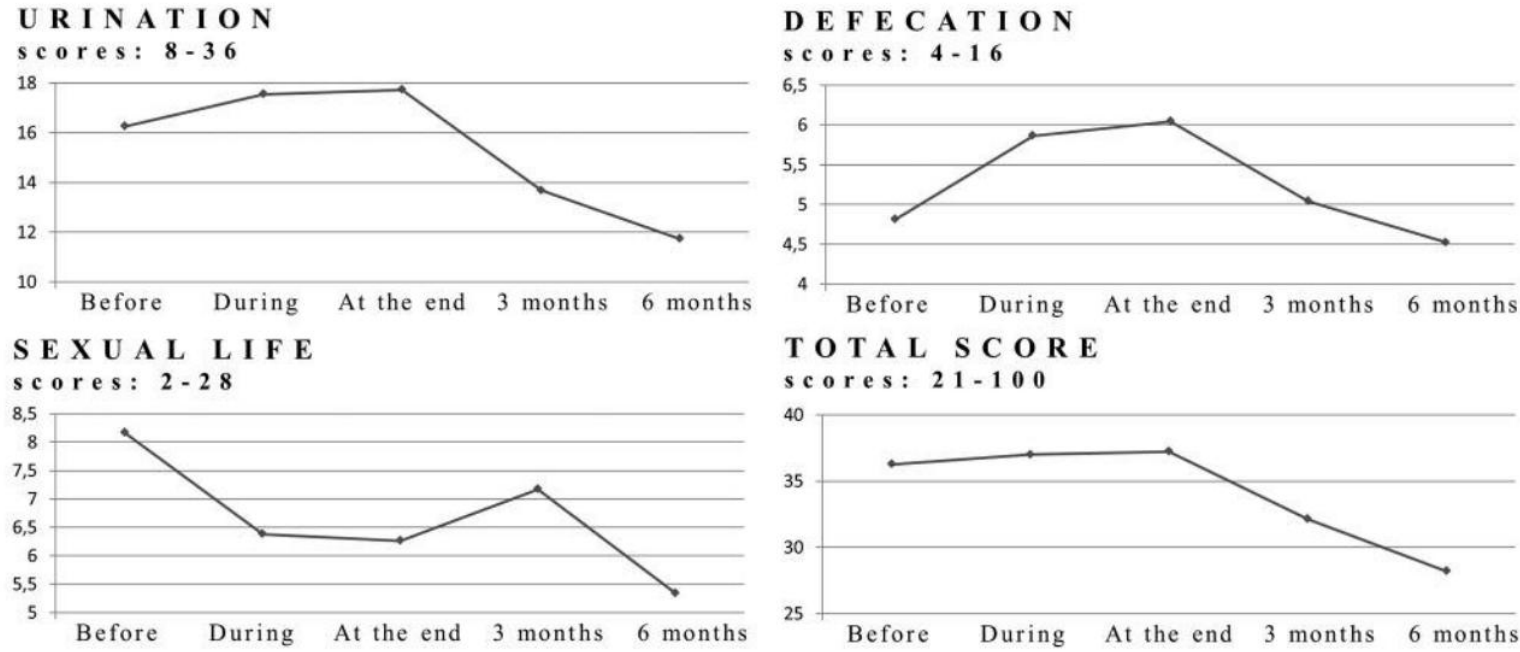

Fig.9. Evaluation of the EORTC QOL questionnaire: lower score is more favourable.

Scores of IPSS questionnaire regarding quality of life were similar to these data, such as prostate specific symptoms: no significant worsening could be detected during the therapy; however significant improvements were registered during the follow-up visits (Figure 10).
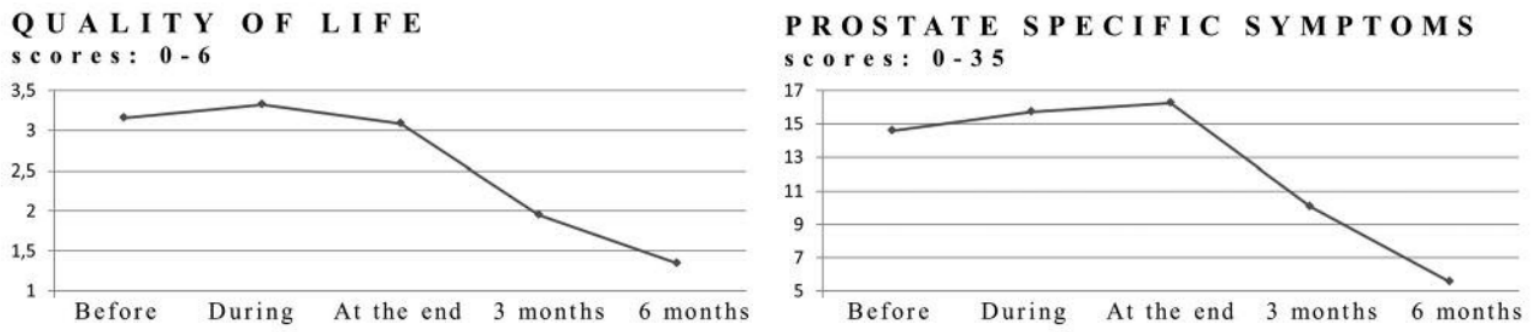

Fig.10. Evaluation of IPSS questionnaire: lower score is more favourable

\subsection{Possible predictive factors for tailored approach in metastatic hormone-sensitive prostate cancer}

\section{Patient characteristics}

55 patients were included in the study, most patients $(94.5 \%)$ had high-volume disease (presence of visceral metastases and/or $\geq 4$ bone metastases with at least 1 outside the vertebral column and pelvis - CHAARTED study definition) [29]. Most of them also had 
Gleason score $\geq 8$ (mean value $8.67 \pm 0.14$ ). At the time of diagnosis, the mean PSA level of patients was $629.6 \pm 161.7 \mathrm{ng} / \mathrm{ml}$.

The mean age $65.6 \pm 1.1$ years (range: $43-79$ ), performance status was generally good (ECOG 0: $67.3 \%$; ECOG 1: 27.3\%, ECOG $25.5 \%$ ). The histo-logical type of prostate cancer was adenocarcinoma in all cases.

\section{Response and survival}

Between the initiation of ADT and docetaxel ChT the mean time was $73.9 \pm 3.9$ days. The mean number of given docetaxel cycles was $5.69 \pm 0.17$. RFS and OS were 10.5 \pm 3.2 months and $40.4 \pm 8.9$ months, respectively.

PSA response was detected in 51 cases $(92.7 \%)$, the mean rate of decrease was $84.7 \pm 4.1$ $\mathrm{ng} / \mathrm{ml}, 80 \%$ of the patients (44) had more than $50 \%$ PSA decrease, the nadir PSA level was $34.0 \pm 19.8 \mathrm{ng} / \mathrm{ml}$.

Castration-resistant PC developed in 32 patients (58.2\%), out of which 23 cases (41.8\% of all patients) were detected within 12 months from the initiation of docetaxel ChT. The mean OS after the development of castration-resistant status was $17.2 \pm 5.4$ months.

By the time of study completion, 17 patients had died (30.9\%), due to prostate cancer 14, 1 due to the development of pneumonia after ChT, 1 due to ileus after ChT, and 1 due to subsequently detected advanced colorectal cancer.

Disease progression was mostly detected with increasing PSA levels in 31 patients $(56.4 \%)$, out of which $19(34.5 \%)$ were bone, 8 (14.5\%) were visceral, and 4 (7.3\%) were distant lymph node metastases.

\section{Clinical factors and outcome}

There was no significant association between RFS/OS and age, Gleason score, initial PSA level, the type of involved organs, or the number of docetaxel cycles.

Performance status, PSA response (Figure 11), only biochemical or oligo-progression were associated with better clinical outcomes (Table 6). Compare to progression after 12 month, 
the progression within 12 months from the initiation of docetaxel ChT was associated with poorer OS (40.4 \pm 8.9 months vs. $17.97 \pm 7.6$ months, $\mathrm{p}<0.001)$.
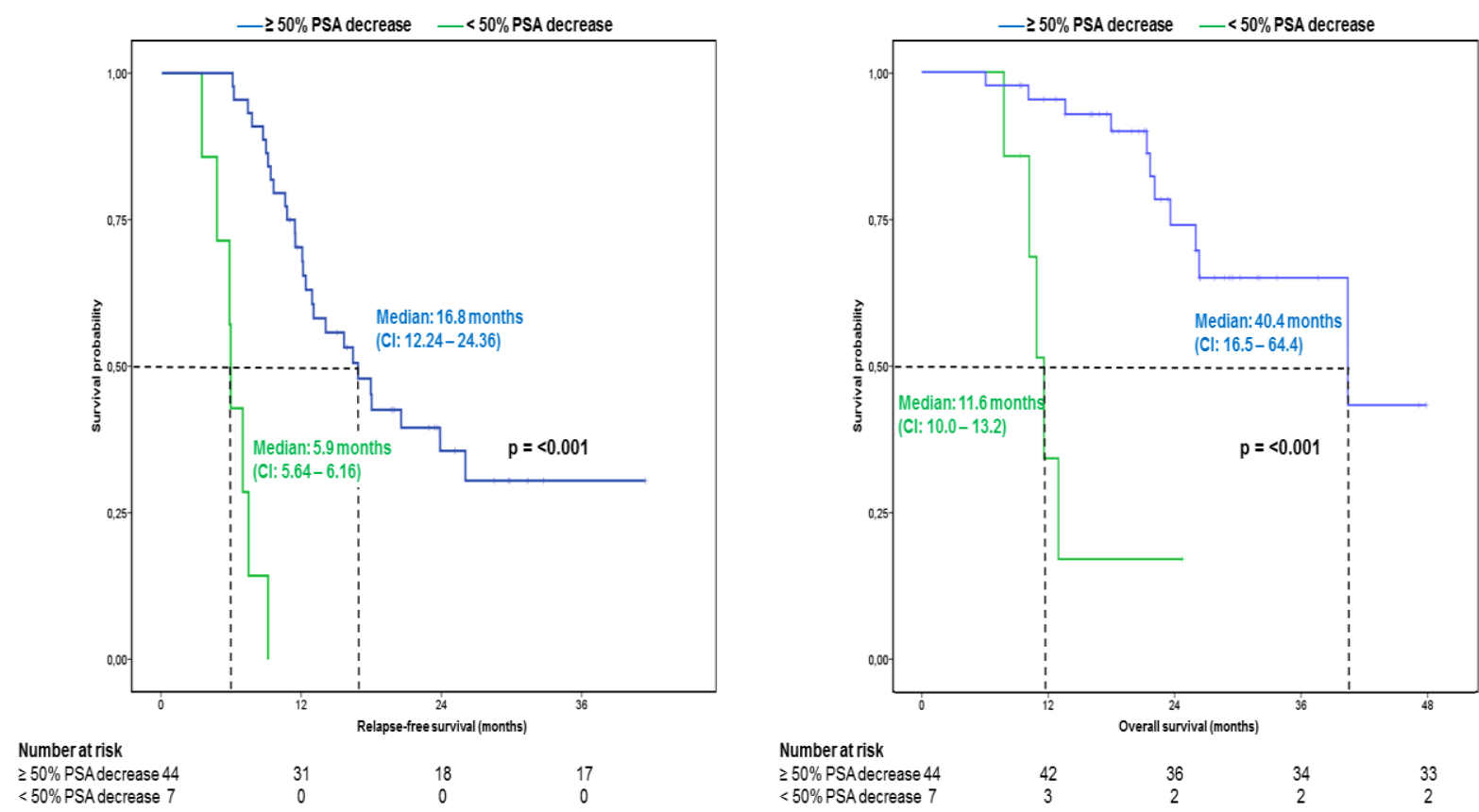

Fig.11. RFS and OS as a function of PSA decrease

(CI: confidence interval; PSA: prostate-specific antigen)

\begin{tabular}{|c|c|c|c|c|}
\hline & RFS (mean \pm SE - months) & $\mathrm{p}$ value & OS (mean $\pm \mathrm{SE}-$ months) & $\mathrm{p}$ value \\
\hline \multicolumn{5}{|c|}{ ECOG } \\
\hline 0 & $17.9 \pm 4.6$ & \multirow{3}{*}{0.002} & $40.43 \pm 9.4$ & \multirow{3}{*}{0.002} \\
\hline 1 & $8.9 \pm 2.1$ & & $25.7 \pm 3.7$ & \\
\hline 2 & $9.1 \pm 6.6$ & & $10.2 \pm 7.5$ & \\
\hline \multicolumn{5}{|c|}{$\geq 50 \%$ PSA decrease } \\
\hline yes & $16.8 \pm 2.3$ & \multirow{2}{*}{$<0.001$} & $40.4 \pm 12.2$ & \multirow{2}{*}{$<0.001$} \\
\hline no & $5.9 \pm 0.1$ & & $11.6 \pm 0.8$ & \\
\hline \multicolumn{5}{|c|}{ PSA progression } \\
\hline yes & $11.4 \pm 0.8$ & \multirow{2}{*}{$<0.001$} & $40.4 \pm 11.6$ & \multirow{2}{*}{0.323} \\
\hline no & $45.3 \pm 1.7$ & & $30.5 \pm 3.2$ & \\
\hline \multicolumn{5}{|c|}{ Number of organs in progression } \\
\hline 1 & $40.2 \pm 2.8$ & \multirow{2}{*}{$<0.001$} & $40.4 \pm 8.9$ & \multirow{2}{*}{0.011} \\
\hline more & $10.8 \pm 0.9$ & & $23.6 \pm 2.9$ & \\
\hline
\end{tabular}

Table 6. Clinical factors associated with survival 
ERG expression was detected in 21 patients (42\%). ERG positivity significantly associated with a lower frequency of early progression: progression within 12 months was detected in 5 ERG positive patients vs. in 16 ERG negative patients $(23.8 \%$ vs. $55.2 \%$, p = 0.026). ERG positivity was significantly associated with better RFS compared to ERG negativity (median RFS: 26.0 vs. 11.4 months, $\mathrm{P}=0.030$ ) (Figure 12 ). There was no statistically significant association between ERG status and OS ( $\mathrm{p}=0.107)$.

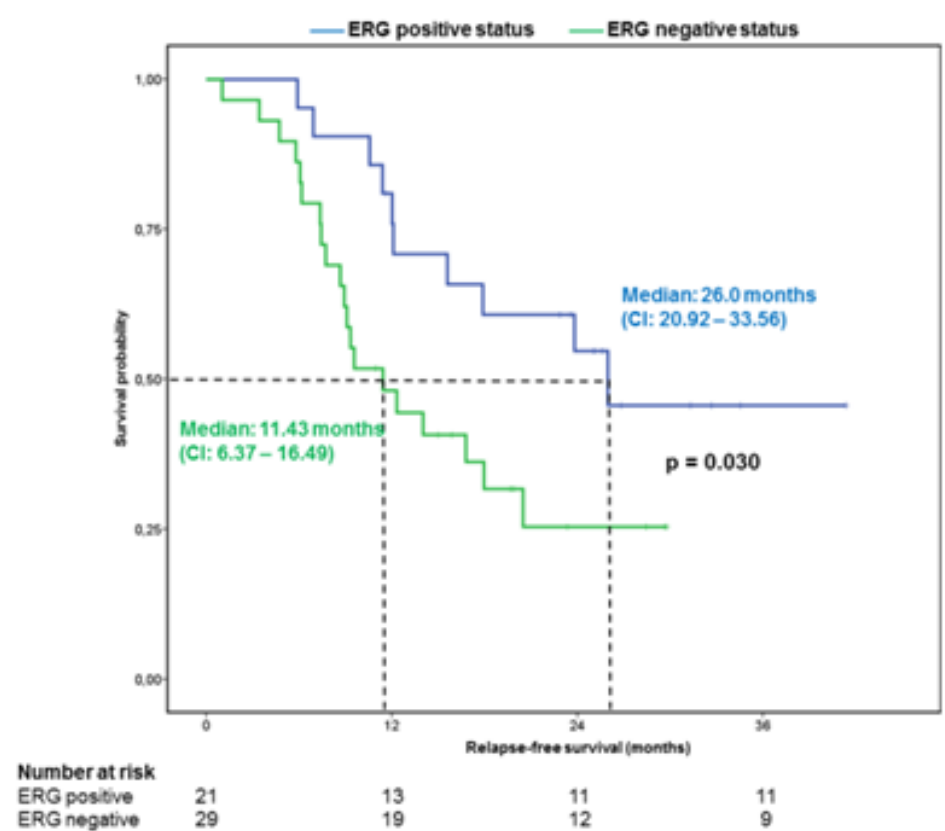

Figure 12. Effect of ERG overexpression on relapse-free survival $(\mathrm{CI}=$ confidence interval; $\mathrm{RSF}=$ relapse-free survival $)$ 


\section{Discussion}

\subsection{Prone positioning on a belly board decreases rectal and bowel doses in pelvic intensity-modulated radiation therapy (IMRT) for prostate cancer}

During the last 20 years many prospective randomized clinical studies have proven that local dose escalation significantly improves biochemical control [3, 4]. Clinically localized highrisk prostate cancer frequently shows micrometastatic spreading to the pelvic lymph nodes; therefore, RT and two/three years of androgen suppressing endocrine treatment are the standard of care. However there is no consensus recommendation for patient selection for pelvic RT in this population, considering the increased exposure of OARs and toxicity [2].

Based on the literature and our work despite the elevated dose in the target volume, the dose of OARs can be reduced without increased toxicity, using modern RT [5, 9], positioning and immobilization techniques [10-11, 30-33].

Radiation exposure of intestines is better in prone position with the use of $\mathrm{BB}$, than in supine position, in case of 3DCRT and IMRT technique, which may decrease the GI morbidity in itself [10]. Gonzalez et al. [11] found that a significantly smaller volume of the small intestine receives more than $20 \mathrm{~Gy}$ dose in prone position with the use of $\mathrm{BB}$, while the interfraction dose variation to the small bowel was similar to the supine position.

Regarding patient positioning, Zelefsky et al. [32] and McLaughlin et al. [33] have described, and also been confirmed in the phase II trial of O'Neil et al. [34] significantly lower rectal doses in prone position, using 3DCRT technique. They could not confirm it in the case of urinary bladder, but the planning was made with empty urinary bladder. Bajon et al. [30] have shown decreased dose exposure of the urinary bladder in prone position besides sparing the rectum and the small intestine. A full bladder functions as a natural spacer, transposing the small intestine loops from the pelvis to the abdomen, resulting in a reduction in the irradiated small intestine volume [35].

In prone position, the decreased rectal exposure is a result of the posterior retraction of the rectum and anterior displacement of the prostate; however, the accurate mechanism of it is unknown [32, 33, 36]. 
Our study was limited by the lack of delineating the penile bulb, and the relatively small number of patients involved, which however double the number of patients, was previously reported.

\subsection{Daily setup accuracy, side-effects and quality of life during and after prone positioned prostate radiotherapy}

With the use of IG-IMRT patient setting errors can be eliminated, so accuracy of spatial dose delivering can be increased, that may lead to improved clinical results [36]. In case of prostate cancer patients, the extent of radiotherapy safety zone (CTV-PTV margin) is being studied (recommendations are available from $1 \mathrm{~mm}$ to $10 \mathrm{~mm}$ ) [9], it can be decreased by marking and mask fixation. Determination of the proper safety zone has to be estimated by the different institutions taking local conditions into consideration.

For further decrease of the safety zone, besides the precise patient positioning and daily IGRT, the transperineal gold marker implantation was introduced in our Institute, according to Jorgo et al. [38]. According to our results, abdominal positioning can be properly performed in IMRT irradiation of high risk PC patients. Using belly board and mask fixation, vertical and lateral setting accuracy detected with $\mathrm{CBCT}$ is similar to the literature.

As the technique of radiotherapy has improved and patient's overall survival has increased, the incidence of side effects and the way they influence the patients' QOL became important [3, 32, 37, 39]. Acute side-effects (mainly cysto-urethritis and radiation induced enteritisproctitis) develop during radiotherapy (usually from the 6th week) and cease on the first follow-up visit after therapy (2-3 months). Late toxicities usually develop 90 days after completion of radiotherapy and include: chronic cystitis, incontinence, urethral stricture, chronic proctitis and rectal bleeding.

In 2011, Beckendorf et al. [3] published the 5-year follow-up study of 70 Gy contra 80 Gy dose escalations: better 5-year biochemical relapse-free survival was detected in case of highdose RT. Side-effects were similar in the two arms, however higher proportion of rectal (proctitis, rectal bleeding) and urinary (cystitis, haematuria, urinary obstruction) toxicities were detected in the 80 Gy group. 
In 2017, Sasaki et al. [39] published their long-term outcomes of the effect of fraction dose reduction (2.2 Gy to $2 \mathrm{~Gy} /$ fraction) to late GI toxicity by using helical tomotherapy and IMIGRT. They found that the reduced dose fraction schedule decreased the incidence of late GI toxicity without compromising prostate-specific antigen control.

Unlike Sasaki, Jorgo at al. [40] prospectively investigated the acute and late toxicity after moderate hypofractionation RT with simultaneous integrated boost for patients with intermediate and high risk localized, locally advanced and node positive prostate cancer. According them results it was feasible, safe and seems to be associated with a tolerable frequency and severity of acute GU and GI toxicities. The rate of severe late GI and UG toxicities are low and comparable to rates with conventionally fractionated treatments.

The change in patients' QOL during RT is tolerable, urination and defecation function deteriorated as previously described. Improvements 3-6 months after RT may demonstrate rapid recovery of acute adverse events and treatment efficacy.

The limitation of this study is its relatively small number of patients. The late toxicities and the QOL after pelvic IMRT for prostate cancer are under further examination.

\subsection{Possible predictive factors for tailored approach in metastatic hormone-sensitive prostate cancer}

We investigated the potential relationship between clinical and immune-histochemical factors, and response to docetaxel therapy in mHSPC patients treated with early docetaxel and ADT.

The possible correlation between ERG expression and outcome of docetaxel chemotherapy in combination with ADT in patients with $\mathrm{mHSPC}$ was has already been presented by Küronya in her PhD thesis.

The combined docetaxel + ADT regimen was well-tolerated; no new adverse events were recorded. ERG positivity and good PSA response were strongly associated with better relapse-free survival.

In 2015 the introduction of early docetaxel to ADT in the hormone-sensitive phase opened up new perspectives in the management of mHSPC. However, certain aspects need to be 
considered in the indication of therapy, and also biomarkers can help predicting the response to Cht.

In the phase III GETUG-12 and GETUG-15 studies docetaxel-based chemotherapy was associated with improved RFS in ERG positive patients, but not in ERG negative patients, suggesting a potential role for ERG as an important biomarker of the effectiveness of docetaxel chemotherapy [41]. In our present study, ERG positivity was also significantly associated with better RFS and a lower frequency of early progression, than ERG negative status among mHSPC patients treated with early docetaxel and ADT.

Moreover, the finding that good PSA response was associated with better RFS is in line with previous observations suggesting a predictive value for PSA progression in terms of survival in metastatic prostate cancer [42].

Our work supplements the existing knowledge base with new data from mHSPC patients receiving the early docetaxel + ADT regimen, although we have to know our limitations: the small sample size and the retrospective nature of our research. 


\section{Summary, conclusions}

6.1. We found prone-positioned pelvic IMRT can be properly carried out in case of high risk PC patients. It decreases the irradiated bowel volumes, and contributes to rectal sparing. The relative dose reduction in the rectal exposure might be a consequence of the slight departure between the prostate wall and the rectal wall, as consistent with the literature, and the increasing volume and diameters of the rectum generated by the displacement of rectal gases.

6.2. IMRT radiotherapy in the prone position can be properly carried out in case of high risk PC patients. Using belly board and mask fixation, vertical and lateral setting accuracy detected with CBCT is similar to the literature.

6.3. GU/GI side effects of this therapy were tolerable. Change of patients' quality of life is insignificant during RT, while improvement 3 and 6 months after RT may be due to rapid recovery from side-effects and effectiveness of therapy. Late toxicities need further examination.

6.4. We suggest that performance status, PSA response, ERG, only biochemical or oligoprogression were associated with better clinical outcomes. Large multicentric, prospective studies are would be necessary to further investigation the role of ERG and other biomarkers in identifying mHSPC patients who would have benefit from the addition of early docetaxel to ADT. 


\section{Acknowledgements}

At the end of my thesis I would like to thank all those people who made this work possible and provided an unforgettable experience for me.

First of all I am most grateful to my supervisor, Anikó Maráz, whose encouragement and generous support helped me in the completion of this thesis. Her patience, guidance and motivation helped me all the time during the research and writing this dissertation.

I wish to express my special thanks to Professor Zsuzsanna Kahán the former, and to Professor Judit Oláh the current director of the Department of Oncotherapy, University of Szeged, who provided excellent working condition for me at the institute.

I would like to express my sincere gratitude to Katalin Hideghéty, Adrienn Cserháti, whose invaluable support significantly contributed my scientific work, and Zoltán Varga, for the guidance in statistical analysis.

Special thanks are due to Zsófia Küronya, Renáta Kószó, Kitti Müller, Emese Fodor, Barbara Darázs, Emőke Borzási, Zoltán Végváry, without whom this task would never have been fulfilled.

Particular thanks to all the Colleagues at the Department of Oncotherapy, University of Szeged. Although they were very busy with their daily tasks, they have always been available to support and guide me, sometimes even in the form of fatherly advice.

I am grateful for the contribution of the colleagues at the uro-oncological board, at the Department of Pathology and Department of Urology, University of Szeged, and the National Institute of Oncology, Budapest.

I greatly appreciate all the support and work of high standard provided by physicians, technicians and physicists of the Department of Oncotherapy, University of Szeged.

Lastly, but most importantly I wish to thank to my family and friends for their unconditional love, care and measureless patience; my gratitude to them is beyond words. 


\section{References}

1. Ferlay J, Shin HR, Bray F, et al. Estimates of worldwide burden of cancer in 2008: Globocan 2008. Int J Cancer 127:2893-2917 2010.

2. Horwich A, Hugosson J, de Reijke T et al. Prostate cancer: ESMO Consensus Conference Guidelines 2012. Ann Oncol 24(5): 1141-1162, 2013.

3. Beckendorf V, Guerif S, Le Prisé E, et al. 70 Gy versus 80 Gy in localized prostate cancer: 5-year results of GETUG 06 randomized trial. Int J Radiat Oncol Biol Phys 80: 1056-1063, 2011.

4. Zelefsky MJ, Pei X, Chou JF, et al. Dose Escalation for prostate cancer radiotherapy: predictors of long-term biochemical tumor control and distant metastases-free survival outcomes. Eur Urol 60(6): 1133-1139, 2011.

5. Andreyev HJ Gastrointestinal problems after pelvic radiotherapy: the past, the present and the future. Clin Oncol (R Coll Radiol) 19:790-799 2007.

6. Theis V, Sripadam R, Ramani V, et al. Chronic radiation enteritis. Clin Oncol 22:70-83 7. 2010.

7. Kennedy G, Heise C Radiation colitis and proctitis. Clin Colon Rectal Surg 20:64-72 8. 2005.

8. Olopade F, Norman A, Blake P, et al. A modified inflammatory bowel disease questionnaire and the Vaizey incontinence questionnaire are simple ways to identify patients with significant gastrointestinal symptoms after pelvic radiotherapy. Br J Cancer 92:166316702005.

9. Nabavizadeh N, Elliott DA, Chen Y, et al. Image Guided Radiation Therapy (IGRT) practice patterns and IGRT's impact on workflow and treatment planning: Results from a national survey of American Society for Radiation Oncology Members. Int J Radiation Oncol Biol Phys 94: 850e857, 2016.

10. Wiesendanger-Wittmer EM, Sijtsema NM, Muijs CT and Beukema JC: Systematic review of the role of a belly board device in radiotherapy delivery in patients with pelvic malignancies. Radiother Oncol 102: 325-334, 2012. 
11. Gonzalez VJ, Hullett CR, Burt L, et al. Impact of prone versus supine positioning on small bowel dose with pelvic intensity modulated radiation therapy. Adv Radiat Oncol2(2): 235243, 2017.

12. Huggins C, Hodges CV Studies on prostatic cancer. I. The effect of castration, of estrogen and androgen injection on serum phosphatases in metastatic carcinoma of the prostate. CA Cancer J Clin. 1972 Jul-Aug;22 (4):232-40.

13. Z Küronya, K Bíró, L Géczi, et al. Treatment strategies for advanced prostate cancer Magy Onkol, 59 (3) (2015), pp. 229-240 Hungarian

14. PA Humphrey, H Moch, AL Cubilla, et al. The 2016 WHO classification of tumours of the urinary system and male genital organs-part B: prostate and bladder tumours Eur Urol, 70 (1) (2016), pp. 106-119

15. C Darr, U Krafft, B Hadaschik, et al. The Role of YKL-40 in predicting resistance to docetaxel chemotherapy in prostate cancer Urol Int, 101 (1) (2018), pp. 65-73 View Record in Scopus Google Scholar

16. P Rescigno, D Lorente, D Dolling, et al. Docetaxel treatment in PTEN- and ERG-aberrant metastatic prostate cancers Eur Urol Oncol, 1 (1) (2018), pp. 71-77

17. G Galletti, A Matov, H Beltran, et al. ERG induces taxane resistance in castrationresistant prostate cancer Nat Commun, 5 (2014), p. 5548, 10.1038/ncomms6548

18. Mellinger GT, Gleason D, Bailar J 3rd The histology and prognosis of prostatic cancer. $\mathbf{J}$ Urol 97:331-337 1967.

19. Sobin LH, Gospodarowicz MK, Wittekind C TNM classification of malignant tumors, 7th edn. Wiley-Blackwell, London 2009.

20. Lawton CAF, Michalski J, El-Naga I, et al. RTOG GU radiation oncology specialists reach consensus on pelvic lymph node volumes for high-risk prostate cancer. Int $\mathbf{J}$ Radiat Oncol Biol Phys 74:383-387 2009.

21. van Herk M, Remeijer P, Rasch C, Lebesque JV.: The probability of correct target dosage: dose-population histograms for deriving treatment margins in radiotherapy., Int $\mathbf{J}$ Radiat Oncol Biol Phys 47(4): 1121-1135, 2000. 
22. U.S. Department of Health and Human Services, National Institutes of Health, National Cancer Institute: Common Terminology Criteria for Adverse Events (CTCAE), Version 4.0; Published: May 28, 2009 (v4.03: June 14, 2010).

23. Borghede $\mathrm{G}$ and Sullivan M: Measurement of quality of life in localized prostatic cancer patients treated with radiotherapy. Development of a prostate cancer-specific module supplementing the E0RTC QLQ-C30. Qual Life Res 5: 212-222, 1996.

24. Barry MJ, Fowler FJ, O'leary MP, et al. The American Urological Association Symptom Index for Benign Prostatic Hyperplasia. J Urol 197: S189-S197, 2017.

25. https://ecog-acrin.org/resources/ecog-performance-status

26. Sonpavde G, Pond GR, Armstrong AJ et al. Radiographic progression by Prostate Cancer Working Group (PCWG)-2 criteria as an intermediate endpoint for drug development in metastatic castration-resistant prostate cancer. BJU Int. 2014 Dec;114(6b):E25-E31. doi: 10.1111/bju.12589. Epub 2014 Jul 17.

27. Mottet N, Bellmunt J, Bolla M et al. EAU-ESTRO-SIOG Guidelines on Prostate Cancer. Part 1: Screening, Diagnosis, and Local Treatment with Curative Intent. Eur Urol. 2017 Apr;71(4):618-629. doi: 10.1016/j.eururo.2016.08.003. Epub 2016 Aug 25.

28. Weinmann S, Van Den Eeden SK, et al. Immunohistochemical expression of ERG in the molecular epidemiology of fatal prostate cancer study. Prostate 2013;73:1371-7.

29. Sweeney CJ, Chen YH, Carducci M, et al. Chemohormonal Therapy in Metastatic Hormone-Sensitive Prostate Cancer. N Engl J Med. 2015 Aug 20;373(8):737-46. doi: 10.1056/NEJMoa1503747. Epub 2015 Aug 5.

30. Bajon T, Piotrowski T, Antczak A, et al. Comparison of dose volume histograms for supine and prone position in patients irradiated for prostate cancer -A preliminary study. Rep Pract Oncol Radiother 16(2): 65-70, 2011.

31. Miyamoto J, Michaud AL, Harandi NK, et al. The role of image-guided radiotherapy in the treatment of anorectal cancer using prone belly-board positioning. Anticancer Res 36: 30133018, 2016. 
32. Zelefsky MJ, Happersett L, Leibel SA, et al. The effect of treatment positioning on normal tissue dose in patients with prostate cancer treated with three-dimensional conformal radiotherapy. Int J Radiat Oncol Biol Phys 37(1): 13-19, 1997.

33. McLaughlin PW, Wygoda A, Sahijdak W, et al. The effect of patient position and treatment technique in conformal treatment of prostate cancer. Int J Radiat Oncol Biol Phys45 (2): 407-413, 1999.

34. O’Neil L, Armstrong J, Buckney S, et al. A phase II trial for the optimisation of treatment position in the radiation therapy of prostate cancer. Radiother Oncol 88:61-66 2008.

35. Kim TH, Kim DY, Cho KH et al. Comparative analysis of the effects of belly board and bladder distension in postoperative radiotherapy of rectal cancer patients. Strahlenther Onkol 181(9):601-605 2005

36. Kato T, Obata Y, Kadoya $\mathrm{N}$ et al. A comparison of prone three-dimensional conformal radiotherapy with supine intensity modulated radiotherapy for prostate cancer: which technique is more effective for rectal sparing? Br J Radiol 82:654-661 2009

37. Crehange G, Mirjolet C, Gauthier M, et al. Clinical impact of margin reduction on late toxicity and short-term biochemical control for patients treated with daily on-line image guided IMRT for prostate cancer. Radiother Oncol 103(2): 244-246, 2012.

38. Jorgo K, Ágoston P, Major T, et al. Transperineal gold marker implantation for imageguided external beam radiotherapy of prostate cancer. Strahlenther Onkol 193: 452-458, 2017.

39. Sasaki N, Yamazaki H, Shimizu D, et al. Long-term outcomes of a dose-reduction trial to decrease late gastrointestinal toxicity in patients with prostate cancer receiving soft tissuematched image guided intensity-modulated radiotherapy. Anticancer Res 38: 385391, 2018.

40. Jorgo K, Polgar CS, Major T, et al. Acute and Late Toxicity after Moderate Hypofractionation with Simultaneous Integrated Boost (SIB) Radiation Therapy for Prostate Cancer. A Single Institution, Prospective Study, Pathology \& Oncology Research

https://doi.org/10.1007/s12253-019-00623-2 2019.

41. Rajpar S, Carmal A, Merabet Z, Vielh P, Foulon S, Lesaunier F. et al. The benefit of combining docetaxel to androgen deprivation therapy in localized and metastatic castration- 
sensitive prostate cancer as predicted by ERG status: an analysis of two GETUG phase III trials. Presented at the 2017 ASCO Annual Meeting on 5 June 2017. Available at: https://www.urotoday.com/conference-highlights/asco-2017/asco-2017-prostatecancer/96278-asco-2017-the-benefit-of-combining-docetaxel-to-androgen-deprivationtherapy-in-localized-and-metastatic-castration-sensitive-prostate-cancer-as-predicted-by-ergstatus-an-analysis-of-two-getug-phase-iii-trials.html.

42. M Hussain, B Goldman, C Tangen, et al. Prostate-specific antigen progression predicts overall survival in patients with metastatic prostate cancer: data from Southwest Oncology Group Trials 9346 (intergroup study 0162) and 9916 J Clin Oncol, 27 (15) (2009), pp. 24502456 
9. Appendix 